\title{
A new species of Slender Stonebasher within the Hippopotamyrus ansorgii complex from the Cunene River in southern Africa (Teleostei: Mormyriformes)
}

\author{
Bernd Kramer $^{\mathrm{a} *}$ and Ernst R. Swartz ${ }^{\mathrm{b}}$ \\ ${ }^{a}$ Zoological Institute, University of Regensburg, D-93040 Regensburg, Germany; ${ }^{b}$ South African \\ Institute for Aquatic Biodiversity, Private Bag 1015, Grahamstown, 6140, South Africa
}

(Received 10 August 2009; final version received 5 March 2010)

\begin{abstract}
Previous work has revealed that Hippopotamyrus ansorgii (Boulenger, 1905) is a species complex, with specimens from the Upper Zambezi system (Caprivi Strip in Namibia) that are well differentiated from the Angolan type specimens. Here, we sampled the Cunene River, one of several possible type rivers for $H$. ansorgii, on the border between Namibia and Angola. The specimens are morphologically differentiated from the six other known morphs within the $H$. ansorgii species complex, including the types and H. szaboi. The electric organ discharge of the Cunene specimens has a different pulse waveform and associated amplitude spectra to that of the three Upper Zambezi system morphs of the species complex. The Cunene specimens are genetically distinct, but relatively closely related to other taxa of the $H$. ansorgii complex, such as the Upper Zambezi system morphs. We recognize the Lower Cunene morph as the new species, Hippopotamyrus longilateralis sp. nov.
\end{abstract}

Keywords: Mormyridae; allopatric speciation; electric organ discharge; molecular genetics; vicariance

\section{Introduction}

The mormyrid fish genus Hippopotamyrus is defined on certain skeletal characters (Taverne 1971b) and comprises about 16 species in tropical and subtropical Africa. The southern African species of this genus, called Hippopotamyrus ansorgii (Boulenger, 1905) or the slender stonebasher, has been recorded in the Cuanza, Cunene, Okavango, Upper Zambezi, Buzi and Pungwe River systems and in Malawi (Skelton 2001). Despite this widespread distribution, populations are fragmented. The type locality for H. ansorgii was only defined as "between Benguella and Bihé" (Boulenger 1909: 74), which probably refers to the Angolan highlands in the current provinces of Benguela, Huambo and Bié. The mountains in this region give rise to at least five major river systems, one of them being the Cunene River. The latter could therefore be the type river for $H$. ansorgii. A critical comparison among the populations isolated in different river systems is further complicated, because only two syntype specimens and no paratypes were designated for $H$. ansorgii.

A study of the electric organ discharge (EOD) and the genetics of $H$. ansorgii in the Upper Zambezi River system revealed the presence of a species complex rather than a single species (Figure 1), and one morph was described as the new species

\footnotetext{
*Corresponding author. Email: bernd.kramer@biologie.uni-regensburg.de
} 


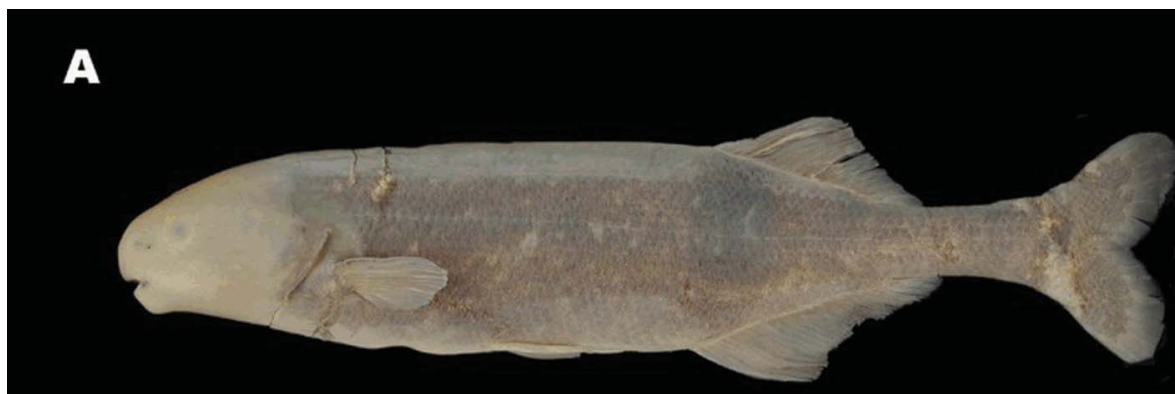

B

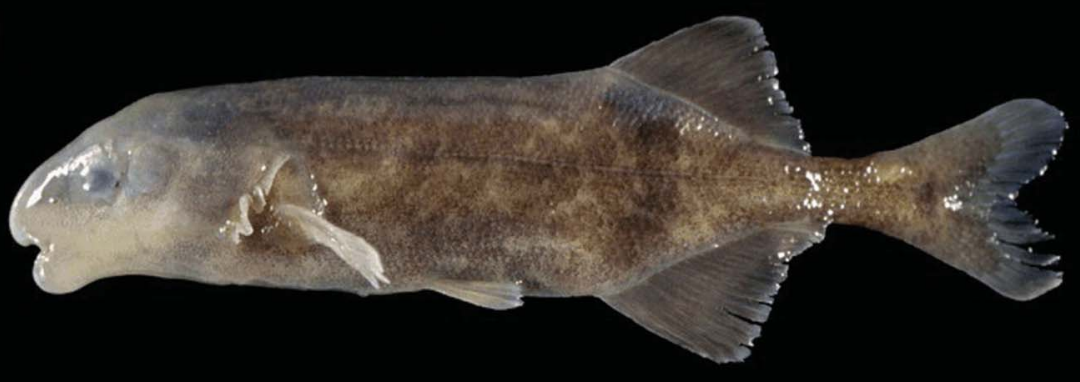

6

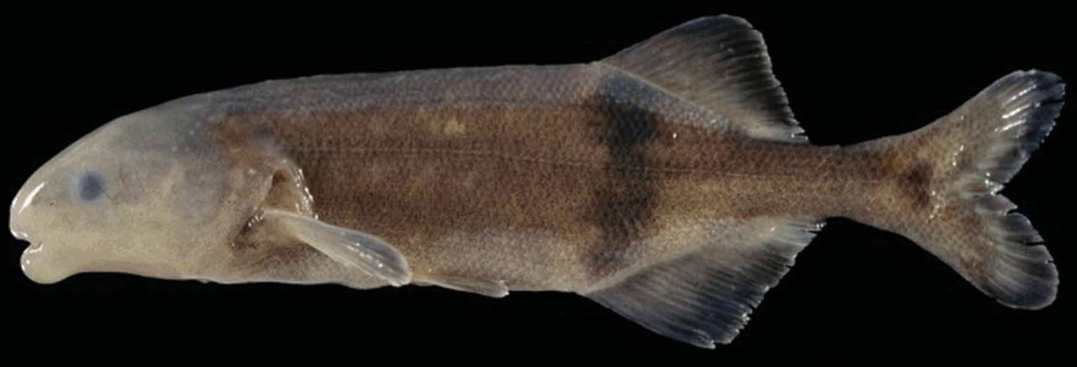

D

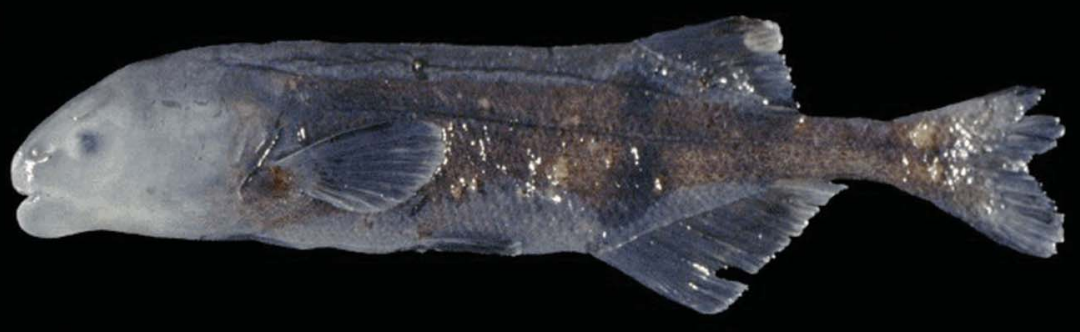

ㅋ.

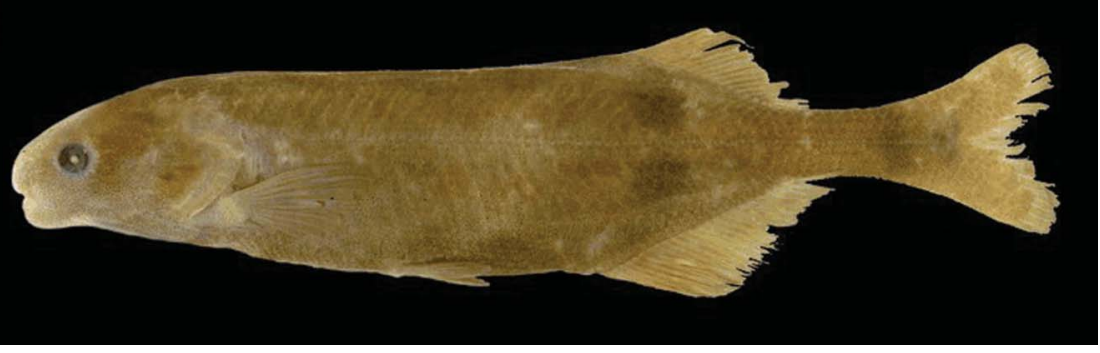


Hippopotamyrus szaboi (Kramer et al. 2004). The other two morphs will be referred to as the Upper Zambezi and the Kwando morphs, based on their original collection localities. The specific status of the latter two morphs remains unresolved, because of insufficient knowledge of the taxonomic diversity within $H$. ansorgii. There are even two morphs from the general type region that are distinct from the types (the Rio Cuchi and the upper Cunene Cukimaala morphs). Although the Upper Zambezi study revealed clear differentiation between sympatric morphs, the question of whether speciation among the geographically isolated populations has occurred remains largely unanswered.

When studying slender stonebashers from the lower Cunene River, it became clear that they belonged to yet another morph of $H$. ansorgii. We compared the EODs, morphology and mitochondrial DNA sequences with all available morphs within the $H$. ansorgii species complex, to determine their taxonomic status. Previous studies of other southern African mormyrid species have been successful using this approach (Kramer et al. 2003, 2004, 2007; Kramer and van der Bank 2000). For more tropical mormyrid species, the usefulness of genetic studies, often in combination with morphological or electrical techniques, was shown by Sullivan et al. (2000, 2002, 2004), Lavoué et al. (2000, 2004), Lavoué and Sullivan (2004), Agnèse and Bigorne (1992), Arnegard and Hopkins (2003), Arnegard et al. (2006) and Feulner et al. (2006, 2007).

In the present study, we compare the new sample from the lower Cunene River with the types and with the five other samples. We tested the hypothesis that the Cunene specimens belong to a different allopatric species within the $H$. ansorgii complex, therefore showing a clear divergence in EODs, morphology and mitochondrial DNA sequences compared with other morphs.

\section{Materials and methods}

\section{Sampling}

Hippopotamyrus specimens were caught with monofilament gill nets and anaesthetized with 2-phenoxy-ethanol after recording EODs from the live specimens. Muscle samples were placed in 98\% ethanol and deposited in the Biomaterial Bank of the South African Institute for Aquatic Biodiversity (SAIAB, Grahamstown). The source specimens and additional voucher specimens were fixed in $10 \%$ formalin and deposited in the ichthyological collection of the same institution and in the Bavarian State Collection, Munich (ZSM, Zoologische Staatssammlung München, Germany). The specimens were collected with permits from the Namibian Ministry of Fisheries and Marine Resources and the ethics of the collecting methods were approved by SAIAB.

\section{Morphology}

In total, 29 specimens from the Cunene River were compared to 97 specimens from Angola and the Namibian part of the Upper Zambezi system (geography, Figure 2). Fifteen anatomical measurements (Figure 3) and four counts were recorded: PDL,

Figure 1. Specimens of the Hippopotamyrus ansorgii species complex. (A) Hippopotamyrus longilateralis (specimen Kune20); (B) Hippopotamyrus szaboi; (C) Upper Zambezi H. ansorgii morph; (D) Kwando H. ansorgii morph; (E) H. ansorgii Type specimen. 


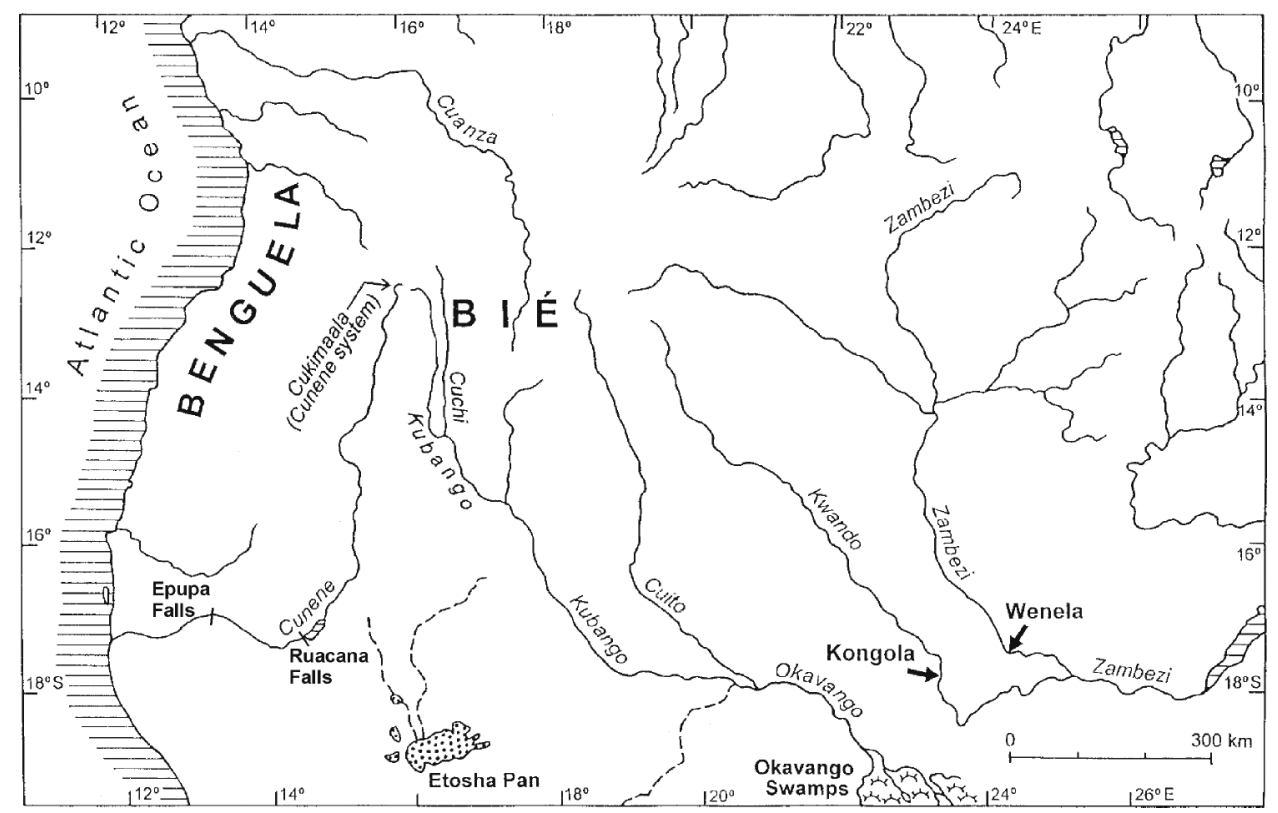

Figure 2. Geography of the study area, with the sites Epupa Falls and Ruacana Falls on the Cunene River (lower Cunene morph), the Wenela site on the Upper Zambezi River (Upper Zambezi morph and Hippopotamyrus szaboi) and the Kongola site on the Kwando River (Kwando morph).

predorsal length (distance from the tip of the snout to the dorsal fin origin); PAL, distance from tip of snout to anal fin origin; LD, dorsal fin length; LA, anal fin length; $\mathrm{pD}$, distance from dorsal fin origin to end of caudal peduncle; CPL, length of caudal peduncle (end of anal fin base to midbase of the caudal fin); CPD, depth of caudal peduncle (the least vertical distance across the caudal peduncle); LSo, length of snout (distance from the tip of the snout to the posterior orbital rim of the eye); LSc, length of snout (distance from the tip of the snout to the centre of the eye - measured but not

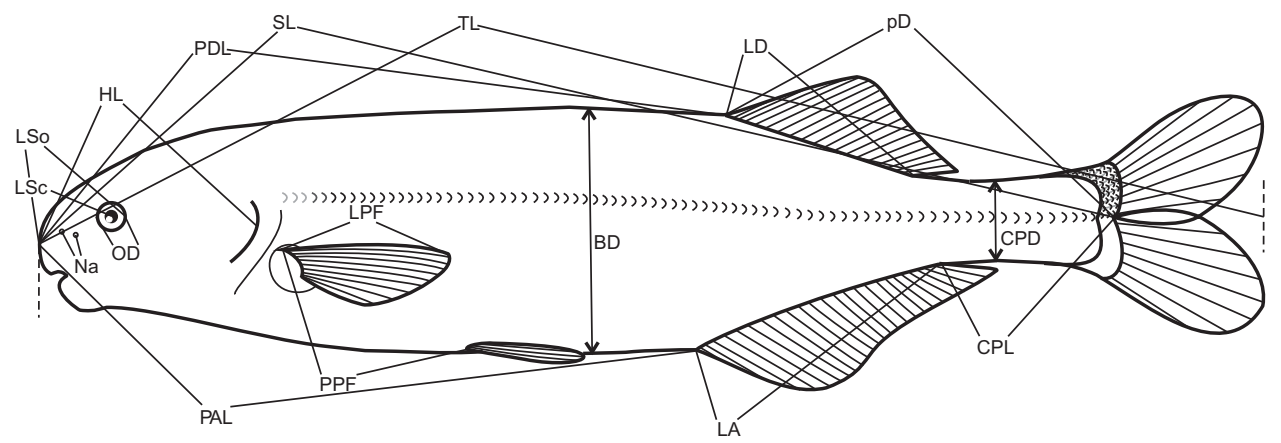

Figure 3. Morphological characters and how they were measured on specimens of the Hippopotamyrus ansorgii species complex. For abbreviations, see the Material and methods section. 
used for redundancy with LSo); HL, head length (distance from the tip of the snout to the furthest bony edge of the operculum); $\mathrm{Na}$, distance between the pair of nares on one side (from centre to centre); OD, eye diameter defined by the orbital rims; LPF, length of the pectoral fins; PPF, distance from the origin of the pelvic fin to the origin of the anal fin (some specimens); SL, standard length (distance between the tip of the snout to the midbase of the caudal fin); BD, body depth (the greatest vertical distance across the body); TL, total length (distance from the tip of the snout to the end of the caudal fin); $\mathrm{nD}$, number of dorsal fin rays; $\mathrm{nA}$, number of anal fin rays; SPc, number of scales around the caudal peduncle; SLS, number of scales in a linear series along the lateral line row, as detailed in Skelton (2001: 67); SLS, range of accuracy \pm 2 counts.

Abbreviations used to represent institutions and collections cited follow Leviton et al. (1985), with the exception of the acronym RUSI which has since been replaced by SAIAB (South African Institute of Aquatic Biodiversity, Grahamstown, South Africa). Specimens examined were initially identified using dichotomous keys in Bell-Cross and Minshull (1988) and Skelton (2001), which are considered effective for fish populations occurring in southern Africa. Abbreviations for species and morphs of the $H$. ansorgii species complex: Hal, Upper Zambezi morph; Ha2, Hippopotamyrus szaboi; Ha3, Kwando morph; Ha4, lower Cunene morph; Ha5, upper Cunene-Cukimaala morph; Ha6, Rio Cuchi morph.

The male sex was inferred when the anal fin base showed a kink, a character also present in many other species of mormyrids.

\section{Electric organ discharges}

The EODs of live fish were recorded in a field laboratory immediately after capture. Measurements were made in a 37-litre plastic aquarium filled with water from the river where the fish was collected. Conditions in the aquarium were kept constant throughout the analysis to exclude the possibility that water quality (especially conductivity) could affect EOD measurements.

Temperature $\left( \pm 0.1^{\circ} \mathrm{C}\right)$ and water conductivity $( \pm 1 \mu \mathrm{S} / \mathrm{cm})$ were constantly monitored using an electronic apparatus (LF318 WTW, Weilheim, Germany). Fish were placed between a pair of carbon rod electrodes that were connected to a differential amplifier with a variable gain (up to $\times 10 ; 0.2 \mathrm{~Hz} \ldots 100 \mathrm{kHz}$; filter slopes, $-3 \mathrm{~dB}$ per octave; electronics workshop, Biology Department, University of Regensburg). Amplifier output was recorded with a digital storage oscilloscope (100 MHz/9 bit/10 000 points per sweep) and data were numerically transferred onto disk via digital interface. Usually eight traces per fish were recorded. All the field equipment was battery operated.

Custom-designed computer programs were used for analysis of EODs (programmed using a software package for signal analysis, FAmOS v5). When necessary, EOD duration was corrected to $25^{\circ} \mathrm{C}$ using a $Q_{10}$ value of 1.5 (Kramer and Westby 1985) before data analysis.

The EOD waveform variables can be defined as follows (compare with Figure 4): Plamp, peak amplitude of positive P1 phase (i.e. from baseline to peak, which is equal to $1 \mathrm{~V}$ by definition); P0amp and P2amp, positive peak amplitudes of pre- and postpotentials, respectively; N0amp and N1amp, negative peak amplitudes of N0 and N1 phases of EOD re: Plamp $=1$; N0dur, P1dur and N1dur, durations of respective 


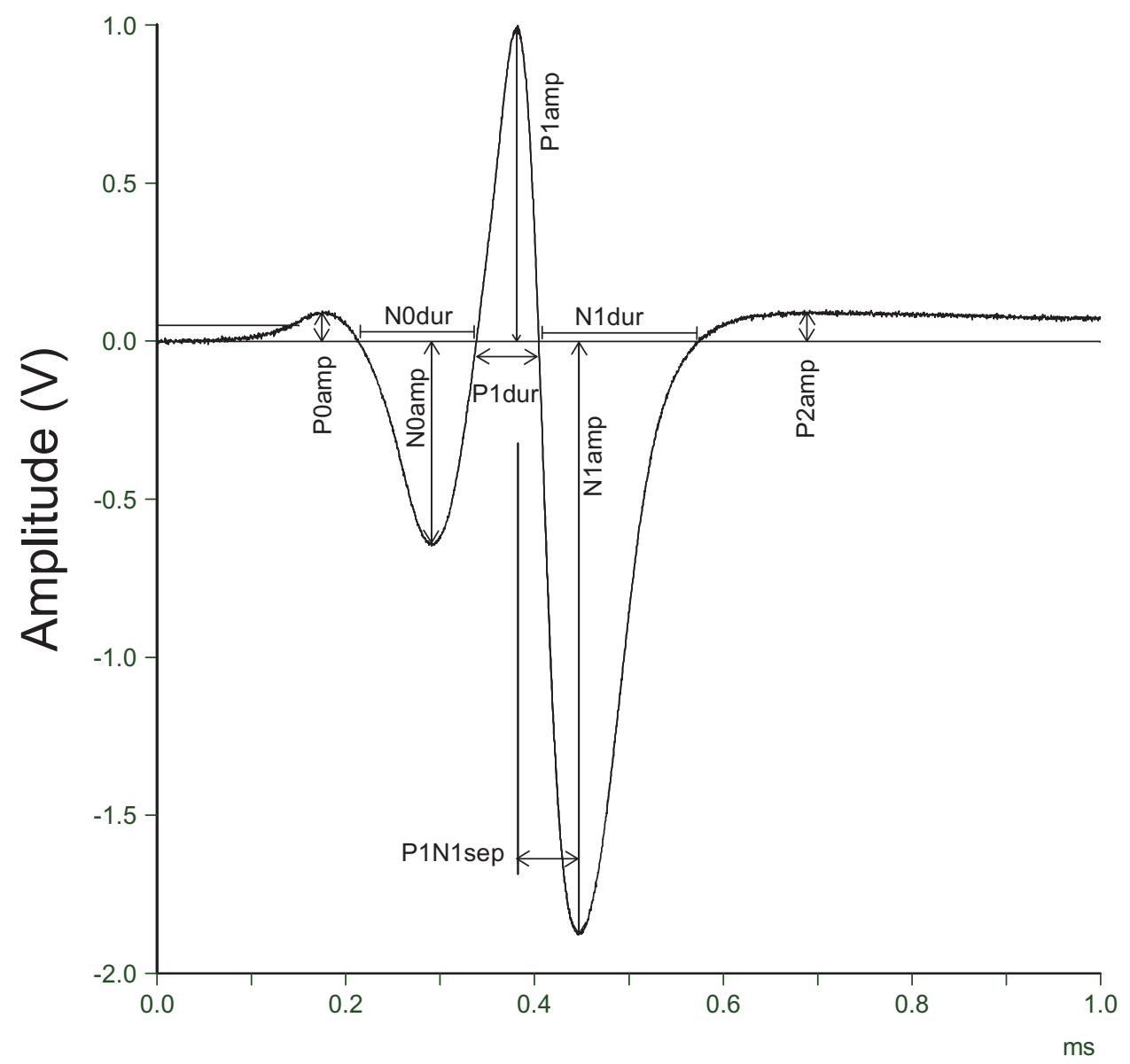

\section{Time (ms)}

Figure 4. Characters of an electric organ discharge (EOD) pulse from the lower Cunene Hippopotamyrus morph, recognized as Hippopotamyrus longilateralis sp. nov., as measured in the present paper. By definition, the positive peak amplitude (P1amp) equals $1 \mathrm{~V}$.

phases; P1N1sep, separation (or interval) between the peaks of the P1 and N1 phases; P1area and N1area, areas under the P1 and N1 phases. Durations in microseconds; amplitudes in relative Volts (re: P1-phase amplitude $=1$ ). Area-under-curve measures, dimension $(\mathrm{V} \times$ microseconds). The start of the initial $\mathrm{P} 0$ phase was determined at a threshold level of 5\% of Plamp; other phases start and end between zero-crossings.

A fast Fourier transform (FFT) routine provided by FAMOs performed amplitude spectra of single EOD pulses. A/D sampling rates were reduced to between 100 and $125 \mathrm{kHz}$. The number of data points for FFT analysis was $2^{19}$, obtained by extending baseline with zeros such that a single EOD per record was centred. Frequency resolution was $<0.24 \mathrm{~Hz}$. 
Subsequent to EOD recording, fish were killed with an overdose of the anaesthetic 2-phenoxy-ethanol. SL was measured with vernier callipers before fixing the specimen in $10 \%$ formalin for morphological studies.

\section{Statistical analysis}

Principal component analyses on correlations among anatomical characters were used to test differences in body shape among populations, because PCA does not require a priori assumptions about taxonomic groups. Analyses of variance (ANOVA) were performed to test the hypotheses of no difference between samples for each character separately. Multivariate analyses of variance (MANOVA; Table 1) were used to prevent overestimating differentiation in testing the hypothesis of no morphological difference between fish from different origins (McGarigal et al. 2000). Values of $p$ were two-tailed unless otherwise stated. We determined the component loadings, i.e. the principal component structure, for interpreting the principal components in terms of the anatomical characters (Appendix 1, Table 3; see McGarigal et al. 2000). We followed Tabachnick and Fidell (2000) to interpret the significance of component loadings. These authors recognize five levels of significance: loadings $>0.32$ or $<-0.32$ are poor, $>0.45$ or $<-0.45$ are fair, $>0.55$ or $<-$ 0.55 are good, $>0.63$ or $<-0.63$ are very good, and $>0.71$ or $<-0.71$ are excellent. These benchmarks account for $10 \%, 20 \%, 30 \%, 40 \%$ and $50 \%$ of the variance in the component. We also performed a discriminant analysis to find the best separation among the lower Cunene, the Upper Zambezi, and the Kwando morphs and H. szaboi in multidimensional space (Figure 5B), using JMP v. 7.0.1 software (SAS Institute, Cary, NC, USA, 2007).

\section{DNA extraction, amplification and sequencing}

Genomic DNA was isolated from the ethanol-preserved tissues using a purification kit (Promega). Amplification by polymerase chain reaction (PCR) of the mitochondrial cytochrome $c$ oxidase I (MT-COI) gene was achieved with the primers VF2T1 5' TGT AAA ACG ACG GCC AGT CAA CCA ACC ACA AAG ACA TTG GCA C 3' and VR1-T1 5' CAG GAA ACA GCT ATG ACT AGA CTT CTG GGT GGC CAA AGA ATC A 3' (Ivanova et al. 2007) and for mitochondrial cytochrome $b$ with the primers GluF 5' AAC CAC CGT TGT ATT CAA CTA CAA 3' (Machordom and Doadrio 2001) and H15917 5' TAG TTG GCC AAT GAT GAT GAA TGG GTG TTC TAC TGG TT 3' (Kramer et al. 2003). Amplification was performed in $25-\mu 1$ volumes containing $1 \times$ buffer, $2.5 \mathrm{~mm} \mathrm{MgCl} 2,0.2 \mathrm{~mm}$ of each of the four nucleotides (ABGENE, Epsom, UK), $1 \mu \mathrm{M}$ of each primer, $1 \mathrm{U}$ of Super-Therm DNA polymerase (ABGENE) and 100-200 ng template DNA. Conditions for the amplification of cytochrome oxidase I (COI) were 3 minutes at $94^{\circ} \mathrm{C}$, then 38 cycles of 30 seconds at $94^{\circ} \mathrm{C}, 30$ seconds at $54^{\circ} \mathrm{C}$ and 50 seconds at $72^{\circ} \mathrm{C}$, finishing with 7 minutes at $72^{\circ} \mathrm{C}$. For cytochrome $b$ the PCR conditions were 4 minutes at $94^{\circ} \mathrm{C}$ with 31 cycles of 45 seconds at $94^{\circ} \mathrm{C}, 1$ minute at $52^{\circ} \mathrm{C}$ and 2 minutes at $72^{\circ} \mathrm{C}$, finishing with 5 minutes at $72^{\circ} \mathrm{C}$. PCR products were sent to Macrogen Inc. (Seoul, Korea) for purification and sequencing. Sequences were deposited in GenBank under accession numbers GU453680-GU453688 and HM065027-HM065034. 


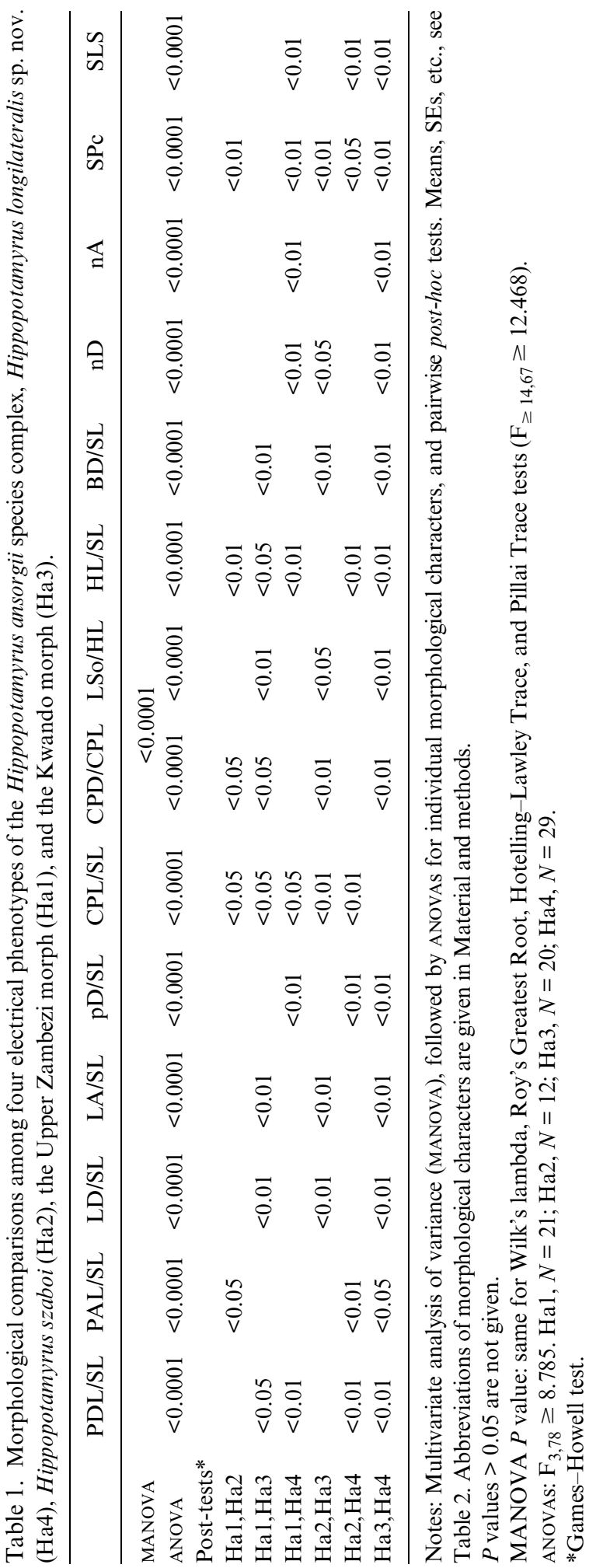



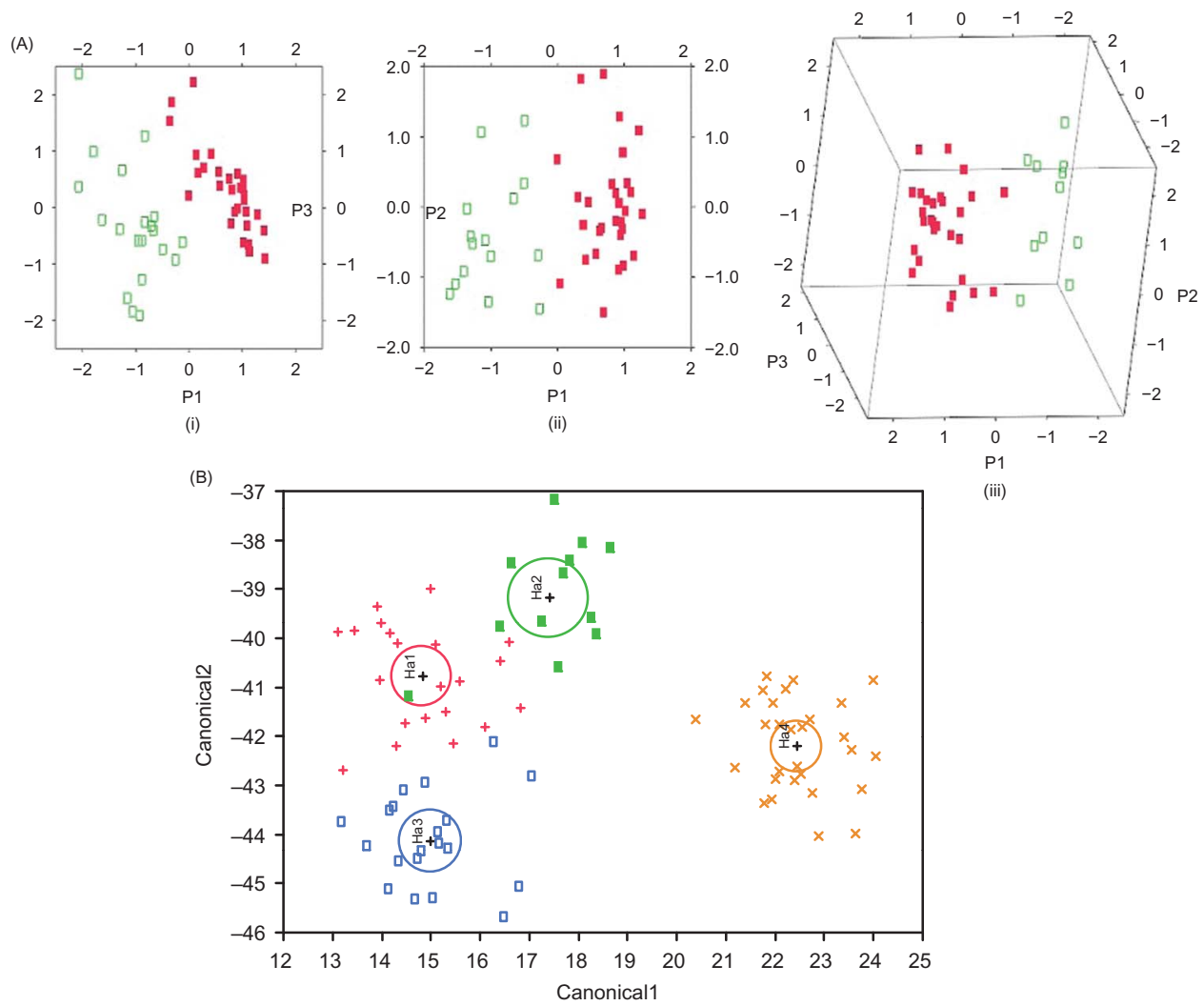

Figure 5. (A) Principal components analysis on 14 morphological characters for Hippopotamyrus szaboi and the lower Cunene, Upper Zambezi and Kwando morphs of the Hippopotamyrus ansorgii species complex. Lower Cunene morph $(n=29$, red filled squares) plotted against (i) the Upper Zambezi morph ( $n=21$, with SLS, green open squares); (ii) Kwando morph ( $n=20$, with SLS, green open squares); (iii) $H$. szaboi $(n=12$, with SLS, green open squares). P1-P3, principal components 1 to 3. (B) Discriminant function analysis on 14 morphological characters for H. szaboi and the lower Cunene, Upper Zambezi and Kwando morphs of the $H$. ansorgii species complex. Lower Cunene morph specimens (orange crosses, $n=29$ ); Kwando morph specimens (blue open squares, $n=20$ ); $H$. szaboi from Upper Zambezi (green solid squares, $n=12$ ); Upper Zambezi morph specimens (red plus signs, $n=21$ ). Circles indicate $95 \%$ confidence limits. [This figure can be viewed in colour online].

\section{Phylogenetic analyses}

Only the cytochrome $b$ sequences were used in phylogenetic analysis because of the availability of outgroups in GenBank. A model of nucleotide substitution that best fitted the sequence data was selected from 56 such models with an Akaike test in MoDELTEST version 3.06 (Posada and Crandall 1998). These parameters were used in a maximum likelihood (Felsenstein 1981) estimation of phylogenetic relationships in the program PAUP* (Swofford 2002) to assess the phylogenetic relationships among the mormyrid species. Starting trees for the maximum likelihood analysis were obtained through the neighbourjoining method (Saitou and Nei 1987). The optimal tree was obtained through a heuristic search with 10 random sequence additions. A parsimony analysis (Hennig 1966) was also 
performed in PAUP* to assess branch support with 10000 non-parametric bootstrap replicates (Felsenstein 1985). Each bootstrap replicate was performed with 10 replicates of random taxon addition. The parsimony analysis was performed using heuristic searches, tree bisection-reconnection branch swapping and 1000 random additions of taxa.

\section{Material examined}

Hippopotamyrus ansorgii (Boulenger, 1905)

Marcusenius ansorgii Boulenger, 1905. Syntypes: BMNH 1905.5.29.62-63 (2) from "Betweeen Benguella and Bihé", Angola.

Marcusenius ansorgii Boulenger, 1905. ZMH 1817. ZMH 1817, upper Cunene Cukimaala morph (also 'morph Ha5'), two specimens, Rio Cukimaala near north Lisboa (which has been renamed Huambo after 1975), a small tributary (headwater) of the Cunene in Angola, leg. Machado, 12 May 1961. The collecting site was at $12^{\circ} 45^{\prime} \mathrm{S}, 15^{\circ} 46^{\prime} \mathrm{E}$ according to P. Skelton (personal communication), based on Penrith (1982), at $1700 \mathrm{~m}$ altitude.

Marcusenius ansorgii Boulenger, 1905. ZMH 1790, Rio Cuchi morph (also 'morph Ha 6'), two specimens, Rio Cuchi in Angola, a tributary of the Kubango (see map of Figure 2), no specific place given, leg. Ladiges and Voelker, 9 October 1961.

Hippopotamyrus ansorgii, Upper Zambezi morph (also 'morph Ha1'). Thirty-four specimens from the Upper Zambezi River, East Caprivi, Namibia,(ZSM 29790, 29792-29807, 17 specimens; and SAIAB 67459, 67461-67464, 67467-67469, 17 specimens): (1) four specimens from Zambezi River, Katima Mulilo, approx. $17^{\circ} 29^{\prime} 30^{\prime \prime} \mathrm{S}, 2^{\circ} 16^{\prime} 18^{\prime \prime} \mathrm{E}, 11$ September 1993; (2) eight specimens from Zambezi River, rapids at Wenela just upstream of Katima Mulilo (border post to Zambia; $17^{\circ} 29^{\prime} 21.5^{\prime \prime} \mathrm{S}, 2^{\circ} 15^{\prime} 33^{\prime \prime} \mathrm{E}$ ), 3-5 April 1996; (3) five specimens from Zambezi River, Wenela, 9 September 1997; (4) six specimens from Zambezi River, Wenela, 23-27 August 1999; (5) 11 specimens from Zambezi River, Wenela, 25 January 2001.

Hippopotamyrus ansorgii, Kwando morph (also 'morph Ha3'). Thirty-six specimens of what is considered a different species of $H$. ansorgii from the Kwando River, Caprivi Strip, Kongola (at bridge of Golden Highway, B8, crossing the Kwando), $17^{\circ} 47^{\prime} 33^{\prime \prime} \mathrm{S}, 23^{\circ} 20^{\prime} 33^{\prime \prime} \mathrm{E}$, (ZSM 29773-29789, 29791, 18 specimens; and SAIAB 67460, 67465, 67466, 18 specimens): (1) four specimens, 9 April 1996; (2) 20 specimens, 26 August 1999; (3) 12 specimens, 24 January 2001.

Hippopotamyrus szaboi Kramer et al. 2004

Hippopotamyrus szaboi Kramer et al. 2004, also referred to as 'morph Ha2' in earlier papers and present crowded Tables. Holotype SAIAB 67143, paratypes SAIAB 67144 (1), SAIAB 67145 (4), ZSM 29765-70 (6), SAIAB 67146 (4), SAIAB 67147 (1), ZSM 29771 (1), ZSM 29772 (1), from Upper Zambezi River, Katima Mulilo, rocks in middle of river, $17^{\circ} 29^{\prime} 30^{\prime \prime} \mathrm{S}, 24^{\circ} 16^{\prime} 18^{\prime \prime} \mathrm{E}$, and Wenela, close by upstream, $17^{\circ} 29^{\prime} 21.5^{\prime \prime} \mathrm{S}, 24^{\circ} 15^{\prime} 33^{\prime \prime} \mathrm{E}$.

Hippopotamyrus longilateralis $s p$. nov.

Hippopotamyrus longilateralis, sp. nov., also referred to as 'morph Ha4'. Holotype SAIAB78793 (field code, Kune20), 25 paratypes: SAIAB79502 (Kune01), SAIAB 79503 (Kune02), SAIAB78778 (Kune03), SAIAB78779 (Kune05, Kune07, Kune08, Kune09, Kune12), SAIAB78793 (Kune22, Kune25), SAIAB78783 (Kune32, Kune34), ZSM38561-ZSM38567 (13 specimens: Kune04, Kune13, Kune15, Kune17, Kune19, 
Kune21, Kune23, Kune26, Kune27, Kune29, Kune30, Kune31, Kune33). From above Epupa Falls on the Namibian/Angolan border, $17^{\circ} 00^{\prime} 07^{\prime \prime} \mathrm{S}, 013^{\circ} 14^{\prime} 57^{\prime \prime}$ E, altitude about $600 \mathrm{~m}$. Additional material from an upstream location just below Ruacana Falls, $17^{\circ} 24^{\prime} 24^{\prime \prime} \mathrm{S}, 014^{\circ} 13^{\prime} 01^{\prime \prime} \mathrm{E}$, about 800 m altitude: SAIAB78787 (three specimens: Ruac04, Ruac05, Ruac08). A total of 22 specimens for EOD, two from Ruacana.

\section{Additional material from which DNA was extracted}

Hippopotamyrus sp. SAIAB 67420: Country: Mozambique Province: Manica Area: Chimanimani Transfrontier Conservation Area System: Buzi River Branch: Mussapa Grande River: Mudzira River Locality: Mudzira River below Mahate 1940'29" S, $33^{\circ} 11^{\prime} 26^{\prime \prime} \mathrm{E}$.

Hippopotamyrus wilverthi SAIAB 79865: Country: Zambia Province: Northern Area: Sumbu System: Lake Tanganyika Water body: Lake Tanganyika Locality: Cape Kashese Harbour $8^{\circ} 29.29^{\prime}$ S, 30²8.47’ E.

Cyphomyrus discorhynchus from Sullivan et al. (2000), CU 79743 from Lake Malawi.

Cyphomyrus psittacus from Sullivan et al. (2000), MNHN 199-610 from the Niger River in Mali.

Marcusenius altisambesi from Kramer et al. (2007), Upper Zambezi (17³2’24" S, $\left.24^{\circ} 32^{\prime} 25^{\prime \prime} \mathrm{E}\right)$.

Pollimyrus castelnaui from Kramer et al. (2003), from the Okavango Delta in Botswana, close to Makwena River Camp near locality Etsha 10, 1903'16.2" S, $22^{\circ} 22^{\prime} 51.3^{\prime \prime}$ E, 20-21 January 2001.

\section{Results}

\section{Anatomical comparisons}

Hippopotamyrus ansorgii (Boulenger, 1905) is morphologically different to the sample from the lower Cunene (Appendix 1, Table 2). The two syntypes do not overlap with the lower Cunene morph $(n=29)$ in their lower SPc (16 versus median 20, range 19-22), lower SLS (max. 72 versus median 76, range 74-78), and lower LSo; they overlap only marginally in their lower $\mathrm{BD}$ and lower $\mathrm{pD}$ (maximum scores for both characters less than the 10th percentiles of the lower Cunene morph).

Hippopotamyrus szaboi and all the other morphs of the $H$. ansorgii species complex also differ morphologically from the lower Cunene morph. The specimens from the upper Cunene in the Cukimaala tributary $(n=2)$ have a greater PAL and Na, and lower scores for $\mathrm{pD}, \mathrm{CPL}, \mathrm{nD}$ and $\mathrm{nA}$. These samples are therefore well differentiated from the lower Cunene morph, despite being from the same river system. The Cuchi River specimens $(n=2)$ differ in having lower SPc counts (16 versus median 20, range 19-22). The 90th percentiles of the lower Cunene morph scores were less than the lower limits of the Cuchi morph specimens in PDL, PAL and Na, whereas the upper limits of the Cuchi morph samples were less than the 10th percentiles of the lower Cunene morph samples in CPD, $\mathrm{nD}$ and $\mathrm{nA}$. The Upper Zambezi morph $(n=29)$ also had lower SPc counts (median 16, range 16-18 versus median 20, range 19-22). It also had lower SLS counts (median 66, range 58-71, versus median 76, range 74-78). In the lower Cunene morph 25th percentile scores were greater than and did not overlap with the 75th percentiles for the Upper Zambezi morph in $\mathrm{pD}, \mathrm{CPL}, \mathrm{nD}$ and $\mathrm{nA}$, whereas the reverse relationship held for HL. The Kwando morph $(n=37)$ differed in a number 
of characters from the lower Cunene morph. The 90th percentile levels for the Kwando morph sample were less than the 10th percentiles for the lower Cunene morph in SPc and SLS. Less extreme differences were found where the 25 th percentiles for the lower Cunene morph were greater than and did not overlap with the 75 th percentiles for the Kwando morph, such as in characters LD, LA, pD, LSo, $\mathrm{nD}$ and $\mathrm{nA}$. The reverse relationship (25th percentiles of the Kwando morph were greater than the 75 th percentiles of the lower Cunene morph) was found for PDL, HL and Na.

The species H. szaboi from the Upper Zambezi River $(n=19)$, showed greater HL scores than the lower Cunene morph samples with no overlap, whereas the 10th percentile for PAL of H. szaboi did not overlap the smaller 90th percentile in the lower Cunene morph. Also PDL and CPD were greater in H. szaboi than in the lower Cunene morph, since the 25 th percentiles of $H$. szaboi did not overlap with the 75 th percentiles in the lower Cunene morph For pD the same, but reversed, relationship was found.

A MANOVA on 14 morphological characters rejected the hypothesis of no difference among the lower Cunene, Upper Zambezi and Kwando morphs and H. szaboi (Table 1). As shown by subsequent ANOVAs followed by post-hoc tests, the lower Cunene morph differed significantly from $H$. szaboi in seven characters, the Upper Zambezi morph in eight characters and from the Kwando morph (the geographically closest population) in 13 characters.

Principal components analysis of correlations on the same 14 morphological characters for the same individuals showed that more than $71 \%$ of the variance among the four samples was explained by the first three components (P1-P3). The analysis therefore successfully reduced redundancy (dimensionality) in the dataset (Appendix 1, Table 3). P1 appears to be a gradient for the length or importance of the rear section of a fish, starting at about the origin of the unpaired fins. Characters that positively loaded on P1 were LA, LD, pD, SLS, SPc (significance all "excellent"), nD ("very good"), nA, BD ("good"), LSo, CPD ("fair"). Negatively correlated with P1 were characters for more frontal body parts such as HL and PDL (significance both "excellent"), and PAL ("poor"). Correspondingly, the characters that correlated positively with P2 were mainly those relating to length or depth of frontal body parts, such as PAL, PDL, HL and BD, but also CPD and LD. The characters that negatively correlated with $\mathrm{P} 2$ were $\mathrm{CPL}$ and $\mathrm{pD}$. Characters loading significantly on P3 did so "poorly", but their main effect was on P1. The only exception was that nA loaded almost as strongly on P1 as it did on P3 (significance "good" in both cases).

Scatter plots in principal component co-ordinates showed separation of data points in different regions of multidimensional space for the lower Cunene morph compared with the Upper Zambezi and Kwando morphs and H. szaboi (Figure 5A). These plots show that the lower Cunene morph tends to have more positive values for P1 than the other three morphs, reflecting the more slender body form of the lower Cunene morph.

The discriminant analysis gave similar results to the principal components analysis (Figure 5B). Among 119 specimens from the lower Cunene, Upper Zambezi and Kwando morphs and H. szaboi, only three were misclassified (3.7\%), none of which were from the lower Cunene morph. One sample each of the Upper Zambezi and Kwando morphs and $H$. szaboi was misclassified as one of the two others, but none were misclassified as the lower Cunene morph.

The specimens from the Namibian section of the Cunene River (between below Ruacana Falls and above Epupa Falls) are therefore morphologically distinct from the six other samples, including the Types. 


\section{EOD comparisons}

Among the members of the $H$. ansorgii species complex studied so far, the lower Cunene form is the only one with a bipolar pulse waveform, as opposed to monopolar, headpositive pulse waveforms for all other forms (Upper Zambezi and Kwando morphs and H. szaboi; Kramer et al. 2004). Whereas the latter forms displayed only weak negative pre- or post-potentials, the EOD of the lower Cunene form was distinctly bipolar and pentaphasic. In addition, to a strong head-positive phase, it had an even stronger headnegative main phase and weaker pre- and post-potentials (Figure 6).

The amplitude spectra of EODs from Cunene specimens therefore had greater bandwidth and higher frequency than all three morphs from the Upper Zambezi River system, the latter with almost pure DC pulses and energy rapidly dropping off with frequency. EODs from the Cunene samples had amplitude spectra that were distinctly bi-lobed, with a low-frequency peak between 520 and $590 \mathrm{~Hz}$ and a second high-frequency peak of similar strength between 4.33 and $5.05 \mathrm{kHz}$. The high-frequency cut-off at $-10 \mathrm{~dB}$ was between 7.45 and $8.89 \mathrm{kHz}$, much higher than in EODs from Kwando morph specimens, whose EODs were the shortest (that is, the highest frequency: $4.6-6 \mathrm{kHz}$ at $-10 \mathrm{~dB}$ ) among the morphs of the Upper Zambezi River system (Figure 7). The strong low-frequency content in Cunene EODs is probably the result of the long duration of the trailing P2 phase, which ends only about 5 milliseconds after the start of the P0 phase.

In the females there was significant correlation with SL in two characters, not observed in males. This negative result for males could be because they are larger $(>15.5 \mathrm{~cm}$ ), except for one specimen. The median was $16.2 \mathrm{~cm}$ for males and $15.2 \mathrm{~cm}$ for females and the size range was $13.1-17.0 \mathrm{~cm}(n=11)$ for males and $11.9-17.4$ $(n=11)$ for females. This difference between the sexes cannot be considered reliable with the current dataset and a more evenly distributed size range of males should be investigated to test this phenomenon in future. In females, P1N1sep and N0dur increased with SL (P1N1sep: $y=0.045+0.002 x, \quad R^{2}=0.386, \quad \mathrm{~F}_{1,9}=5.664$, $p=0.0412$; N0dur: $\left.y=0.017+0.009 x, R^{2}=0.797, \mathrm{~F}_{1,9}=35.34, p=0.0002\right)$. There was no reliable difference between the sexes (Appendix 2, Table 5).

\section{DNA sequence analysis}

In choosing appropriate outgroups, BLAST searches in GenBank and subsequent phylogenetic analyses confirmed that taxa of the mormyrid genera Cyphomyrus, Genyomyrus, Gnathonemus, Ivindomyrus, Marcusenius, Mormyrops, Mormyrus, Paramormyrops, Petrocephalus and Pollimyrus are genetically only distantly related to the lower Cunene Hippopotamyrus morph. Apart from including all available

Figure 6. Electric organ discharge (EOD) pulse waveforms for four specimens representing four morphs of the Hippopotamyrus ansorgii species complex. Note that (D), the lower Cunene morph, has a pentaphasic waveform with strong positive and negative phases, whereas the morphs from the Upper Zambezi River system (A-C) all show essentially monopolar, head-positive EOD pulses (resulting in a strong DC component). (A) Hippopotamyrus szaboi; (B) Upper Zambezi morph of $H$. ansorgii; (C) Kwando River morph of $H$. ansorgii. To the left of each panel, the longest EOD pulse of the whole sample of specimens, respectively, is shown; right, shortest EOD; middle, an EOD of a specimen with near average duration. 

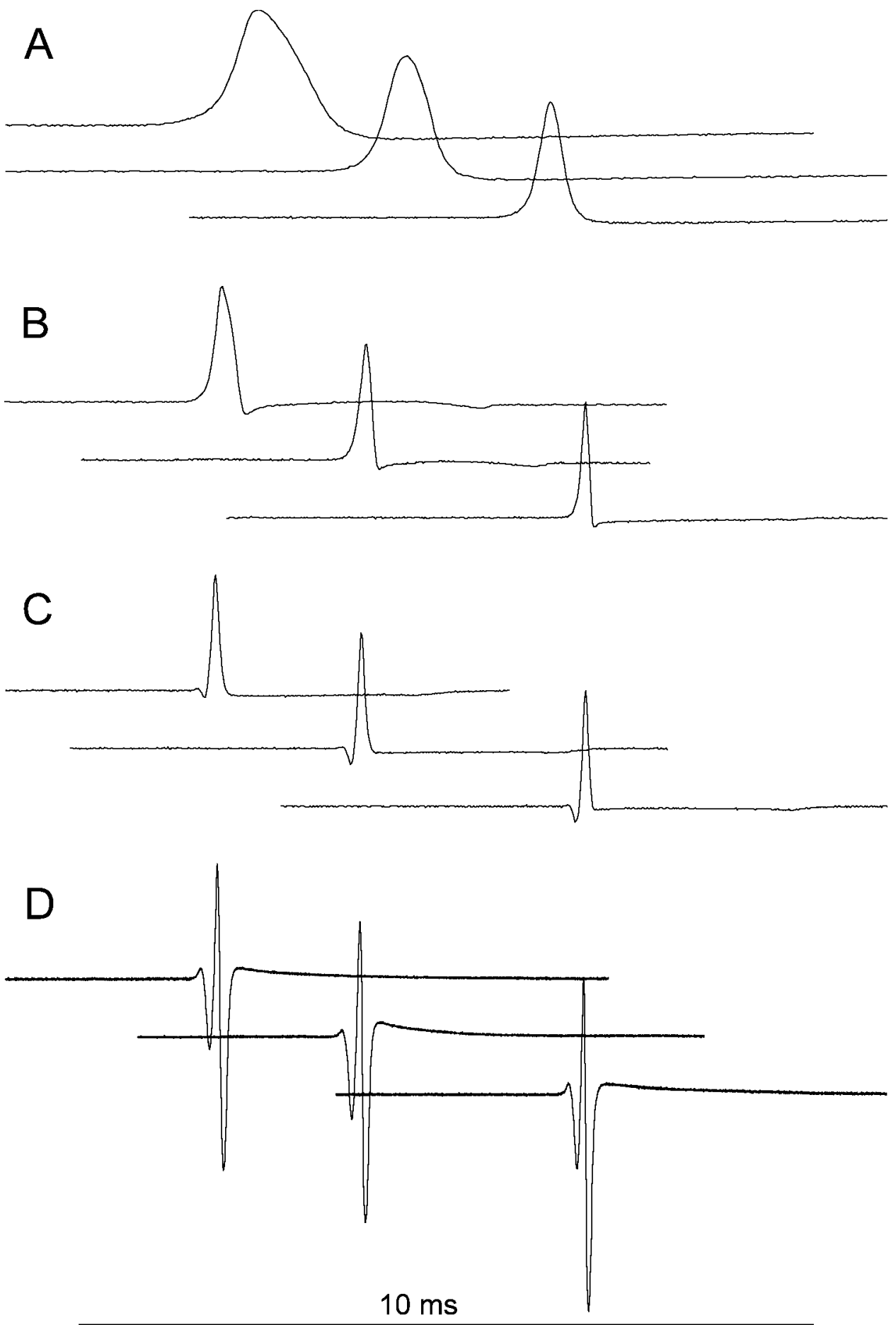


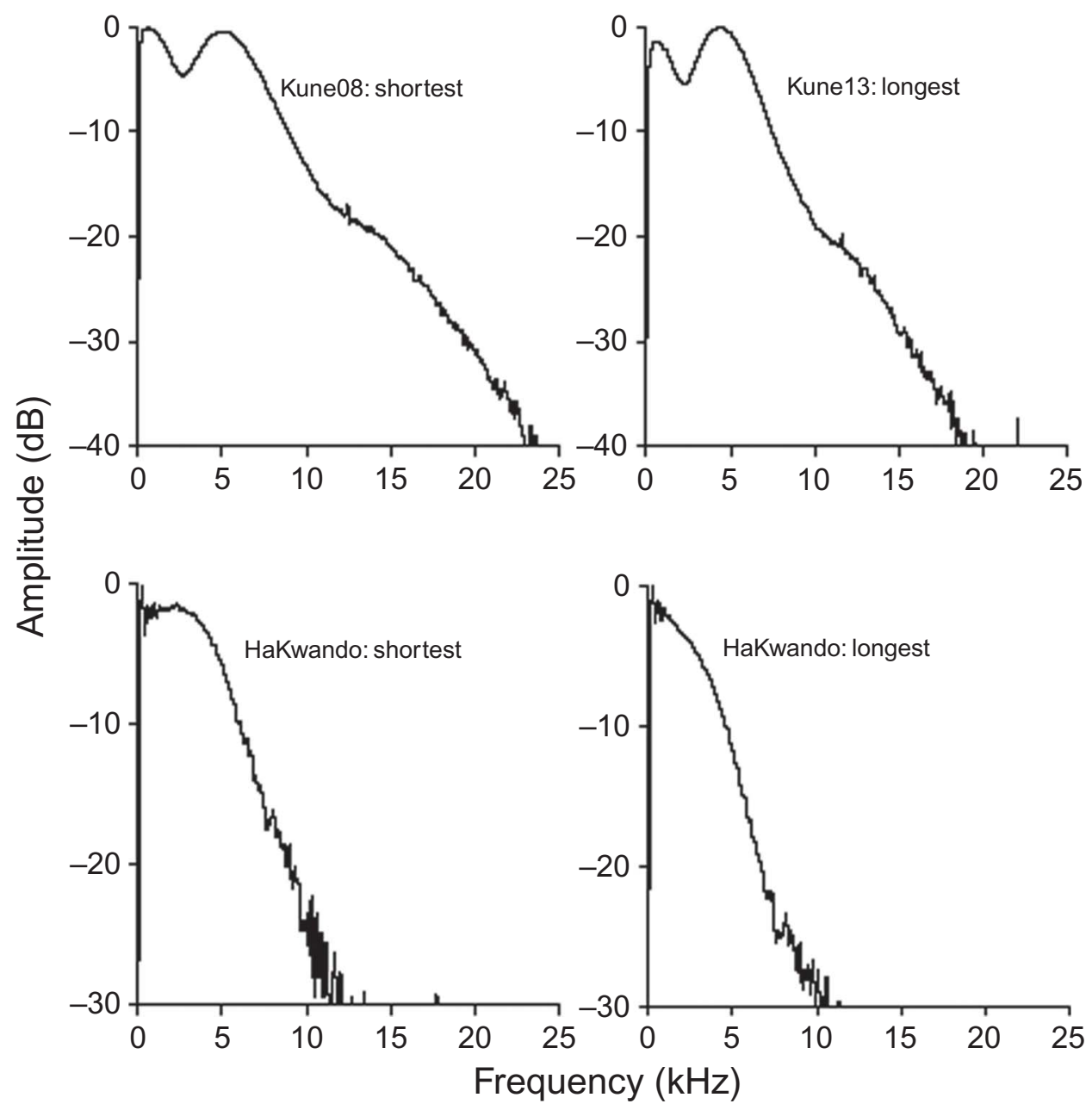

Figure 7. Amplitude spectra for electric organ discharge (EOD) pulses. Top panels, Hippopotamyrus longilateralis (the lower Cunene morph); bottom panels, Hippopotamyrus ansorgii from the Kwando River. Left hand panels, shortest EOD pulses of a sample of specimens, respectively; right hand panels, longest pulses of a sample. The spectra for the Upper Zambezi and Kwando morphs and Hippopotamyrus szaboi all reveal essentially monopolar DC pulses, like those shown on the bottom panels, whereas the spectra for the lower Cunene morph reveal a second peak of higher frequency, resulting from a bipolar, pentaphasic pulse waveform.

Hippopotamyrus specimens and GenBank sequences, it was therefore decided to only include additional sequences of recently studied individuals that were sampled close to their type localities and for which multiple datasets were available. Cyphomyrus psittacus from the Niger River in Mali (Lavoué et al. 2000), Cyphomyrus wilverthi from the Ubangi River in Central African Republic and Cyphomyrus discorhynchus from Lake Malawi (Sullivan et al. 2000), were included as in-group taxa, because they have been regarded as belonging to Hippopotamyrus. Marcusenius altisambesi was included because it may occur in the same river as the lower Cunene Hippopotamyrus morph. 


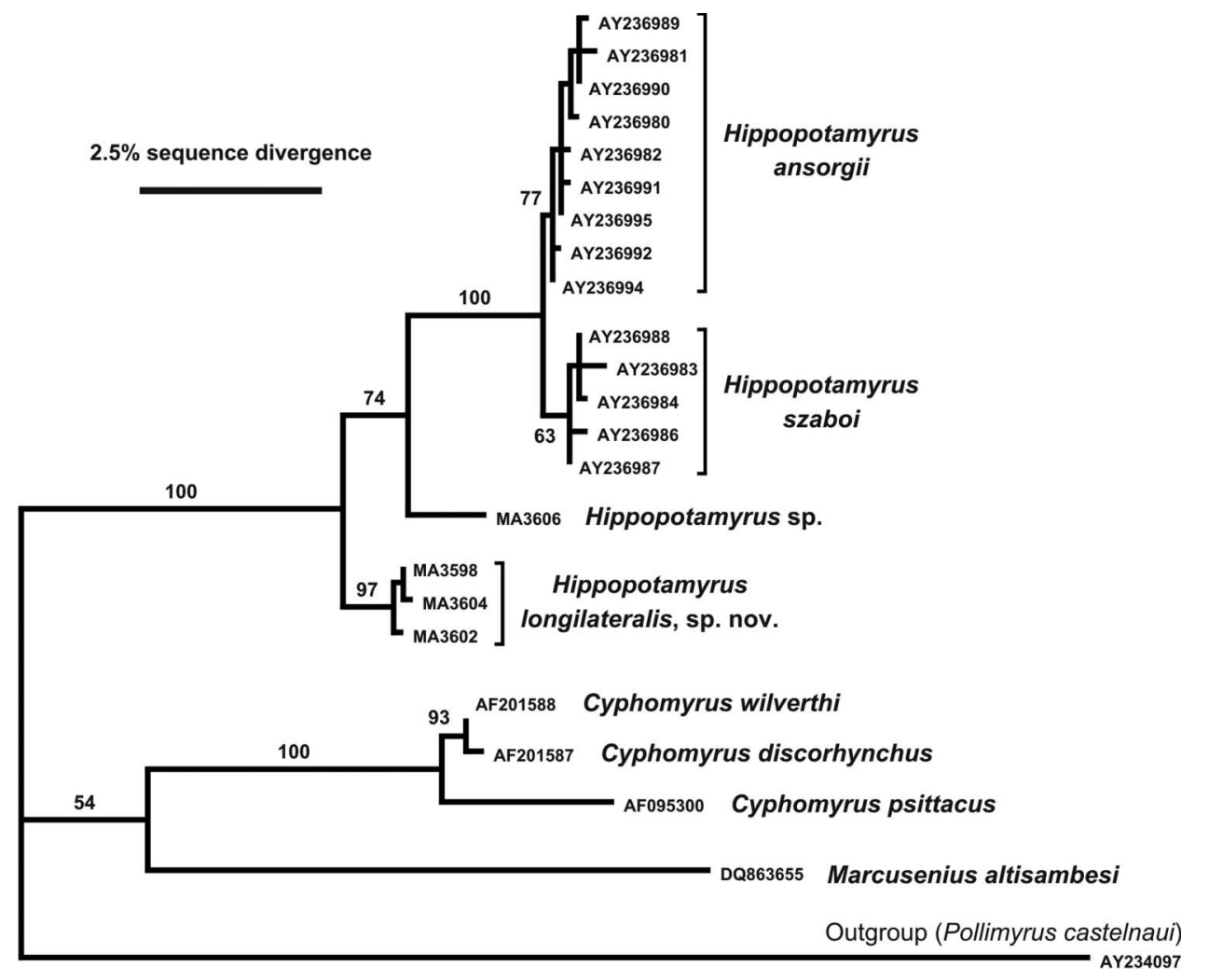

Figure 8. Maximum likelihood phylogram based on mitochondrial cytochrome $b$ sequences from the present study and GenBank, showing the phylogenetic relationships of the lower Cunene Hippopotamyrus morph. Values above the branches are bootstrap support based on 10000 parsimony bootstrap replicates.

The maximum likelihood analysis and the genetic distances among the different taxa were based on the transversional model (TVM) model with a gamma distribution ( $\alpha$ value 0.1745$)$ found in ModeLTEST. The phylogenetic analysis revealed three deep lineages within Hippopotamyrus between a unique Hippopotamyrus lineage from the Buzi River system in Mozambique, the Upper Zambezi River system species and morphs (H. szaboi and the Upper Zambezi and Kwando Hippopotamyrus morphs) and the lower Cunene morph (Figure 8). There was strong bootstrap support for the Hippopotamyrus taxa as a monophyletic group. The lower Cunene Hippopotamyrus morph is therefore closely related but distinct from the other taxa in the $H$. ansorgii complex. All the other species representing the genera Cyphomyrus, Marcusenius and Pollimyrus were only distantly related. The level of divergence between the lower Cunene Hippopotamyrus morph and other taxa of the H. ansorgii complex is comparable with species-level differences in other groups of organisms, with very little intraspecific differentiation $(0.1-0.4 \%)$ compared with interspecific divergence from Hippopotamyrus sp. from the Buzi River system (2.4-2.6\%), Upper Zambezi and Kwando Hippopotamyrus morphs (3.2-3.7\%) and H. szaboi (3.3-4.0\%) 
(Appendix 1, Table 4). The major sequence divergences between the lower Cunene Hippopotamyrus morph and the Cyphomyrus species (7.8-11.4\%), Marcusenius altisambesi (9.5-9.6\%) and Pollimyrus castelnaui (11.9-12.1\%), supports their classification as different genera.

\section{Systematics}

Genus Hippopotamyrus Pappenheim, 1906

\section{Diagnosis (translation of Taverne 1971a)}

Body moderately elongated to elongated; snout shorter than postorbital segment of skull, with upper jaw high, curved downward and somewhat longer than lower jaw; caudal peduncle $2-3 \frac{3}{4}$ times longer than high; 16-41 dorsal fin rays; 22-35 anal fin rays; 10-12 pectoral fin rays; 45-93 lateral line scales; 10-21/14-23 scales transversely to body; 9-19/9-19 scales transversely between dorsal and anal fins; 12-16 scales around caudal peduncle; 3-7/6-10 bicuspid teeth; lateral ethmoid present and well developed; mesethmoid big and curved backwards; five circumorbital bones; preorbital, and first infraorbital fused; five hypural bones; 41 to 48 vertebrae.

Type species

Hippopotamyrus castor Pappenheim, 1906

Included species (from Eschmeyer and Fricke 2010)

aelsbroecki, Gnathonemus Poll 1945. Current status: valid as Hippopotamyrus aelsbroecki (Poll 1945)

aequipinnis, Paramyomyrus Pellegrin 1927. Current status: synonym of Hippopotamyrus castor Pappenheim 1906

ansorgii, Marcusenius Boulenger 1905. Current status: valid as Hippopotamyrus ansorgii (Boulenger 1905)

castor, Hippopotamyrus Pappenheim 1906. Current status: valid as Hippopotamyrus castor Pappenheim 1906

cubangoensis, Marcusenius Pellegrin 1936. Current status: synonym of Hippopotamyrus discorhynchus (Peters 1852)

grahami, Marcusenius Norman 1928. Current status: valid as Hippopotamyrus grahami (Norman 1928)

harringtoni, Marcusenius Boulenger 1905. Current status: valid as Hippopotamyrus harringtoni (Boulenger 1905)

macroterops, Marcusenius Boulenger 1920. Current status: valid as Hippopotamyrus macroterops (Boulenger 1920)

pappenheimi, Marcusenius Boulenger 1910. Current status: valid as Hippopotamyrus pappenheimi (Boulenger 1910)

paugyi, Hippopotamyrus Lévêque and Bigorne 1985. Current status: valid as Hippopotamyrus paugyi Lévêque and Bigorne 1985 
pictus, Petrocephalus Marcusen 1864. Current status: valid as Hippopotamyrus pictus (Marcusen 1864)

retrodorsalis, Marcusenius Nichols and Griscom 1917. Current status: valid as Hippopotamyrus retrodorsalis (Nichols and Griscom 1917)

smithersi, Marcusenius Määr 1962. Current status: synonym of Hippopotamyrus discorhynchus (Peters 1852)

szaboi, Hippopotamyrus Kramer, van der Bank and Wink 2004. Current status: valid as Hippopotamyrus szaboi Kramer, van der Bank and Wink 2004

tanganicanus, Marcusenius Boulenger 1906. Current status: synonym of Hippopotamyrus discorhynchus (Peters 1852)

weeksii, Marcusenius Boulenger 1902. Current status: valid as Hippopotamyrus weeksii (Boulenger 1902)

Hippopotamyrus ansorgii (Boulenger, 1905)

(Figure 1E)

Marcusenius ansorgii Boulenger 1905

Hippopotamyrus ansorgii: Taverne 1971a: 104; Taverne 1971b: 136; Taverne 1972: 170.

\section{Material examined}

See Material and methods section.

Type specimens

Syntypes: BMNH 1905.5.29.62-63 (2).

Type locality

"Betweeen Benguella and Bihé". Benguella district includes the highlands of Bihé (Stieler 1910). The highlands are the origin of at least five major rivers flowing in all directions. The origin of the syntypes will therefore remain unclear until new evidence, possibly from historical notes, can be found giving more precise geographical information (an intensive search has so far been unsuccessful).

\section{Diagnosis}

nA, median 25 (range 24-26); nD, median 18.5 (range 18-19); SPc, median 16 (range 16-16); SLS, median 69.5 (range 67-72); LSo, mean 0.4365 (range 0.4259-0.4470) of HL; BD, mean 0.1966 (range 0.1891-0.240) of SL; HL, mean 0.2109 (range 0.20790.2139 ) of SL; PDL, mean 0.6444 (range 0.6347-0.6542) of SL; PAL, mean 0.6118 (range $0.5990-0.6245)$ of SL; pD, mean $0.3765(0.3669-0.3861)$ of SL.

Hippopotamyrus ansorgii species complex specimens of uncertain status

Marcusenius ansorgii Boulenger, 1905. ZMH 1817. ZMH 1817, two specimens, Rio Cukimaala near north Lisboa (which has been renamed Huambo after 1975), a small tributary (headwater) of the Cunene in Angola, leg. Machado, 12 May 1961. 
Marcusenius ansorgii Boulenger, 1905. ZMH 1790, two specimens, Rio Cuchi in Angola, a tributary of the Kubango (see map of Figure 2), no specific place given, leg. Ladiges and Voelker, 9 October 1961.

Hippopotamyrus ansorgii. SAIAB 67459, 67461-67464, 67467-67469, 17 specimens, and ZSM 29790, 29792-29807, 17 specimens from the Upper Zambezi River (Upper Zambezi morph, morph Ha1), East Caprivi, Namibia.

Hippopotamyrus ansorgii. SAIAB 67460, 67465, 67466, 18 specimens, ZSM 29773-29789, 29791, 18 specimens from the Kwando River (Kwando morph, morph Ha3), Caprivi Strip, Kongola bridge.

Hippopotamyrus szaboi Kramer, Van der Bank and Wink 2004 (Figure 1B)

\section{Material examined}

See Materials and methods section.

\section{Type specimens}

Holotype SAIAB 67143. Paratypes SAIAB 67144 (1), SAIAB 67145 (4), ZSM 29765-70 (6), SAIAB 67146 (4), SAIAB 67147 (1), ZSM 29771 (1), ZSM 29772 (1). (also referred to as 'morph Ha2' in present and earlier paper).

\section{Type locality}

Upper Zambezi River, Katima Mulilo, rocks in middle of river, $17^{\circ} 29^{\prime} 30^{\prime \prime} \mathrm{S}$, $24^{\circ} 16^{\prime} 18^{\prime \prime} \mathrm{E}$.

\section{Diagnosis}

CPL, mean 0.1838 (range 0.1671-0.2145) of SL; SLS, median 67 (range 61-73); PDL, mean 0.6624 (range $0.6337-0.6916$ ) of SL; PAL, mean 0.6282 (range 0.5954-0.6596) of SL; pD, mean 0.3777 (range 0.3452-0.4006) of SL; HL, mean 0.258 (range $0.2349-0.2787$ ) of SL; LSo, mean 0.4824 (range 0.4494-0.5203) of HL; $\mathrm{BD}$, mean 0.2319 (range $0.2018-0.2651$ ) of SL; nD, median 19 (range 18-21); nA, median 22 (range 21-25); head-positive EOD waveform (620-1800 s at 10\% peak amplitude, $\left.25^{\circ} \mathrm{C}\right)$. Mitochondrial cytochrome $b$ DNA sequence, GenBank AY236983-8.

\section{Hippopotamyrus longilateralis sp. nov.}

(Figure 1A)

Material examined

See Materials and methods section. 


\section{Type specimens}

Holotype SAIAB78793, Paratypes SAIAB 79502, 79503, 78778, 78779, 78793, 78783, 78787, ZSM 38561-ZSM 38567.

\section{Type locality}

Cunene River, just above Epupa Falls on the Namibian/Angolan border, $17^{\circ} 00^{\prime} 07^{\prime \prime} \mathrm{S}, 013^{\circ} 14^{\prime} 57^{\prime \prime} \mathrm{E}$, altitude about $600 \mathrm{~m}$.

\section{Diagnosis}

pD, mean 0.4013 (range 0.3791-0.4175) of SL; SLS, median 77 (range 74-80); PDL, mean 0.6273 (range 0.6123-0.6499) of SL; SPc, median 20 (range 19-22); nD, median 20 (range 18-21); nA, median 24 (range 22-25); PAL, mean 0.6020 (range 0.59060.6270 ) of SL; CPL, mean 0.2080 (range 0.1952-0.2202) of SL; HL, mean 0.2155 (range $0.1923-0.2289$ ) of SL; LSo, mean 0.4943 (range $0.4578-0.5484$ ) of HL; BD, mean 0.2256 (range $(0.2037-0.2451$ ) of SL; bipolar, pentaphasic waveform of EOD pulse (bipolar main pulse, about $230 \mu$ s). Mitochondrial cytochrome $b$ and barcode sequences (GenBank, GU453680-GU453688 and HM065027-HM065034).

\section{Description}

Head broadly rounded with a terminally positioned mouth, lower jaw protruding less forward than upper; body long and slender, laterally compressed. Dorsal fin origin set far back and behind that of anal fin, situated about two-thirds of standard length from snout, obliquely orientated with anterior portion of the fin higher than the posterior portion, median number of rays 20 (18-21). Anal fin opposite dorsal fin but origin further anterior and also obliquely orientated, anteriorly lower and posteriorly higher, margin broadly rounded, median number of rays 24 (22-25). Scales cycloid with reticulate striae, except in centre, extending anteriorly to operculum and pectoral fins. SPc, median 20 (19-22). Caudal peduncle slender and subcylindrical over the entire length, usually slightly less than one-fifth in SL. Tail fin with broadly rounded lobes. EOD bipolar and pentaphasic, duration of the two main phases about $230 \mu \mathrm{s}$ but whole pulse may last up to 5 milliseconds because of weak pre- and post-potentials $\left(25^{\circ} \mathrm{C}\right)$. Dark brown with a vertical black band from dorsal origin that is only weak in most specimens.

\section{Colour in preservation}

Dark to medium brown, often with milky-grey hue, especially where opaque 'mormyrid skin' (electroreceptor organ area) present (and not rubbed off the underlying skin).

\section{Ecology}

The section of the Cunene River between Ruacana Falls and Epupa Falls is a permanently flowing river with a strong current. Water level is controlled by a hydroelectric power plant at Ruacana Falls (Namib Power) and a large dam (Calueque Dam) further upstream in Angola. The Ruacana Falls was completely dry during our survey, illustrating the extreme river regulation. A major daily difference in water level was 
even detected at Epupa Falls (a straight line distance from Ruacana Falls of $115 \mathrm{~km}$ ), where catches were good during lower water levels with no fish caught during high flow. Although the area around Epupa Falls is very dry, there are extensive stands of palm (Makalani, Hyphaene petersiana) and other trees, reeds and bushes that grow on the banks, including an occasional baobab. At Ruacana, which is wetter, the arboreal and other vegetation and bird life were more abundant and varied. Crocodiles were present at both Ruacana and Epupa waterfalls, with hippopotamus reported for the former, but not seen. Most of the $H$. longilateralis specimens were caught along well-vegetated and steep banks of the river. They therefore possibly prefer undercut banks with structure such as roots.

\section{Distribution}

Only known from the section of the Cunene River between below Ruacana Falls downstream to above Epupa Falls, a straight-line distance of $115 \mathrm{~km}$. This section of the river forms part of the Namibian/Angolan border.

\section{Relationships}

Based on our phylogenetic analysis, H. longilateralis is the sister-group of all other members of the $H$. ansorgii species complex. Barcode (COI) sequence of paratype specimens were done for future reference.

\section{Etymology}

The specific name longilateralis is in reference to the long lateral line.

\section{Remarks}

Referred to as the lower Cunene morph in the present paper ('morph Ha4' in tables with limited space); H. longilateralis is distinguished by $\mathrm{pD}$ and SLS highest and PDL lowest among the species complex of seven; SPc and $\mathrm{nD}$ also high; distinctive bipolar, pentaphasic waveform of its EOD pulse, as opposed to monopolar DC pulses generated by the Upper Zambezi and Kwando morphs and H. szaboi. The species can also be distinguished on their phylogenetic relationships with mitochondrial cytochrome $b$ and barcode sequences. We therefore recognize the lower Cunene morph as a new species, $H$. longilateralis sp. nov.

\section{Discussion}

The slender stonebasher, H. ansorgii (Boulenger, 1905), is described as a rare, current-loving species with a fragmented distribution in southern Africa (Van der Waal and Skelton 1984; Bell-Cross and Minshull 1988; Skelton 2001). On anatomical, electrical and in part genetic evidence, Kramer et al. (2004) have described six morphs of this species, one of which was recognized as the new species $H$. szaboi. We here present evidence for a seventh morph of the $H$. ansorgii species complex from the lower Cunene River, the new species $H$. longilateralis.

Hippopotamyrus longilateralis is anatomically differentiated from all other known morphs, including the $H$. ansorgii types. Its EOD differs consistently from those of the 
three other morphs that have been studied to date, and it genetically represents a monophyletic and divergent lineage compared with the Upper Zambezi and Kwando morphs, and a specimen from the Buzi River. Hippopotamyrus longilateralis appears to be specifically adapted to strong currents in its escarpment habitat. Their rear section is more strongly developed than in any other morph we have studied (pD and SLS are increased at the expense of PDL). In addition, their bipolar, multiphasic EOD is probably more advantageous than the monopolar DC pulses of its congeners from the Upper Zambezi and the Kwando: (1) reduced predation pressure from sharptooth and other catfish is likely because of less spectral energy in the low-frequency range (Hanika and Kramer 2000); (2) more possibilities in encoding individual differences (potentially of fitness relevance) are offered by a more complex EOD waveform with five phases rather than one (Markowski et al. 2008); (3) better electrolocation performance because a broadband test signal, such as that of $H$. longilateralis, will allow the detection of a broader range of capacitive impedances, such as prey organisms (Lissmann and Machin 1958; Meyer 1982; Von der Emde 1990).

Based on the electrophysiological work of Bennett (1971) and on the modelling approach of Westby (1984), Markowski et al. (2008) have shown that the strikingly different EOD waveforms found in a pair of parapatric sibling snoutfish species from southern Africa (Pollimyrus castelnaui and Pollimyrus marianne), can be mutually transformed to be identical, by making small changes in three physiological variables. EOD waveforms therefore seem to be much more plastic in evolutionary time and may become differentiated in rapidly evolving species more quickly than previously thought.

Genetic distances between $H$. longilateralis and the three morphs from the Upper Zambezi system were between 2.4 and 4\% (Appendix 1, Table 4). A molecular clock of about $2 \%$ sequence divergence in 1 million years has been determined for mitochondrial genes (Wilson et al. 1987). This would correspond to a separation of the Cunene lineage from that of the Zambezi system morphs about 1.2-2 million years ago. Its basal position within this clade testifies to the hypothesis that Angolan rivers are key to understanding the phylogeography of snoutfish populations in southern Africa.

The number of fish common to two rivers divided by the total number of species yields a Similarity Index. A rather high Similarity Index of 0.55 for fish species inhabiting the Cunene and the Okavango suggests a former linkage between the two rivers (Skelton 1994). Such a linkage has been proposed via the ephemeral Colui, which is among the eastern headwaters of the Cunene (Moore and Larkin 2001, p. 66). However, a critical comparison of allopatric populations of $H$. ansorgii has not been made.

The evolution of the Cunene River is not well understood. It is assumed that it flowed into a large lake where the Etosha Pan is now, and was captured by a coastal river eroding backwards (Goudie 2005). The time of this event (which separated the Cunene from the Okavango-Zambezi systems) is not well constrained, and could be a consequence of the opening of the South Atlantic (suggested at about 110-130 million years ago, reviewed in Stankiewicz and de Wit 2006) some time in the Tertiary, or as recent as 35000 years ago (reviewed in Goudie 2005).

The present cytochrome $b$ data point to the lower Pleistocene, when a major rearrangement of the Zambezi River, possibly indirectly affecting the Cunene, occurred. First, inland extension of the headwaters of the short lower Zambezi captured the middle Zambezi via the Kariba gorge, and then the middle Zambezi beheaded the Upper Zambezi via the Batoka gorge, creating the present course of the main Zambezi. This latter event has been dated to 1.25-2 million years ago (reviewed in Moore and 
Larkin 2001; Stankiewicz and de Wit 2006). It is tempting to speculate on the coincidence of the time estimates from the geological and hydrographic data with the molecular clock estimate for the origin of $H$. longilateralis presented in this paper as an example of vicariance affecting the phylogeny of fish.

Any improvement of our present state of knowledge regarding the linked river and fish evolution will only be possible with a better understanding of the Angolan fish fauna and river evolution.

\section{Acknowledgements}

We are grateful to Luis da Costa for organizing the trip, helping to catch fish, and for many fruitful discussions; Mrs Sally Terry for co-organising the trip, overcoming all kinds of technical obstacles, and keeping track with the data base; Paul Skelton for sponsoring the trip, obtaining permissions, and advice and assistance on all levels; Poogendri Reddy for laboratory analysis; Roger Bills, Jerraleigh Kruger and Kholiwe Dubula (all SAIAB) for assistance with the collection; Mrs Mathilde Awasis (National Museum of Namibia, Windhoek) for providing storage space and kindly allowing access to Museum facilities; James Maclaine, BMNH for kindly loaning specimens; Uli Schliewen and Dirk Neumann (ZSM, Munich) for assistance with collection; the Zoologisches Institut and Museum Hamburg for loaning specimens; the Morphology team at Regensburg: Ellen Fröhlich, Birgit Blaul, Sabine Hartl, Andreas Lechner, Thomas Gierl, Silvia Förster, and Dr Eric Hilton for generous, constructive criticism. This work was sponsored by Deutsche Forschungsgemeinschaft, grant Kr 446/12-1.

\section{References}

Agnèse J-F, Bigorne R. 1992. Premières données sur les relations génétiques entre onze espèces ouest-africaines de Mormyridae (Teleostei, Osteichthyes). Rev Hydrobiol Tropic (Bondy). 25:253-261.

Arnegard ME, Bogdanowicz SM, Hopkins CD. 2006. Multiple case of striking genetic similarity between alternate electric fish signal morphs in sympatry. Evolution 59:324-343.

Arnegard ME, Hopkins CD. 2003. Electric signal variation among seven blunt-snouted Brienomyrus species (Teleostei: Mormyridae) from a riverine species flock in Gabon, Central Africa. Environ Biol Fishes (Dordrecht). 67:321-339.

Bell-Cross G, Minshull JL. 1988. The fishes of Zimbabwe. Harare: National Museums and Monuments of Zimbabwe.

Bennett MVL. 1971. Electric organs. In Hoar WS, Randall DJ, editors. Fish physiology. London, New York: Academic Press. p. 347-491.

Boulenger GA. 1905. Descriptions of four new freshwater fishes discovered by Dr. W. J. Ansorge in Angola. Ann Mag Nat Hist (Ser.7). 15:457-459.

Boulenger GA. 1909. Catalogue of the fresh-water fishes of Africa in the British Museum (Natural History). London: British Museum (NH).

Eschmeyer WN, Fricke R. editors. Catalog of Fishes electronic version [Internet]. [cited 2010 Jan 15]. Available from http://research.calacademy.org/ichthyology/catalog/fishcatmain.asp

Felsenstein J. 1981. Evolutionary trees from DNA sequences: a maximum likelihood approach. J Mol Evol. 17:368-376.

Felsenstein J. 1985. Confidence limits on phylogenies: an approach using the bootstrap. Evolution 39:783-791.

Feulner PGD, Kirschbaum F, Mamonekene V, Ketmaier V, Tiedemann R. 2007. Adaptive radiation in African weakly electric fish (Teleostei: Mormyridae: Campylomormyrus): a combined molecular and morphological approach. J Evol Biol. 20: 403-414. 
Feulner PGD, Kirschbaum F, Schugardt C, Ketmaier V, Tiedemann R. 2006. Electrophysiological and molecular genetic evidence for sympatrically occurring cryptic species in African weakly electric fishes (Teleostei: Mormyridae: Campylomormyrus). Mol Phylogen Evol. 39:198-208.

Goudie AS. 2005. The drainage of Africa since the Cretaceous. Geomorphology 67:437-456.

Hanika S, Kramer B. 2000. Electrosensory prey detection in the African sharptooth catfish, Clarias gariepinus (Clariidae), of a weakly electric mormyrid fish, the bulldog (Marcusenius macrolepidotus). Behav Ecol Sociobiol. 48:218-228.

Hennig W. 1966 Phylogenetic systematics. Urbana (IL): University of Illinois Press.

Ivanova NV, Zemlak TS, Hanner RH, Hebert PDN. 2007. Universal primer cocktails for fish DNA barcoding. Mol Ecol Notes. 7:544-548.

Kramer B, Skelton P, van der Bank H, Wink M. 2007. Allopatric differentiation in the Marcusenius macrolepidotus species complex in southern and eastern Africa: the resurrection of M. pongolensis and M. angolensis, and the description of two new species (Mormyridae, Teleostei). J Nat Hist. 41:647-708.

Kramer B, van der Bank FH. 2000. The southern churchill, Petrocephalus wesselsi, a new species of mormyrid from South Africa defined by electric organ discharges, genetics, and morphology. Environ Biol Fishes (Dordrecht). 59:393-413.

Kramer B, van der Bank H, Flint N, Sauer-Gürth H, Wink M. 2003. Evidence for parapatric speciation in the mormyrid fish, Pollimyrus castelnaui (Boulenger, 1911), from the Okavango - Upper Zambezi River Systems: P. marianne sp. nov., defined by electric organ discharges, morphology and genetics. Environ Biol Fishes (Dordrecht). 67:47-70.

Kramer B, van der Bank FH, Wink M. 2004. The Hippopotamyrus ansorgii species complex in the Upper Zambezi River System with a description of a new species, H. szaboi (Mormyridae). Zool Scripta. 33:1-18.

Kramer B, Westby GWM. 1985. No sex difference in the waveform of the pulse type electric fish, Gnathonemus petersii (Mormyridae). Experientia 41:1530-1531.

Lavoué S, Bigorne R, Lecointre G, Agnèse J-F. 2000. Phylogenetic relationships of mormyrid electric fishes (Mormyridae; Teleostei) inferred from cytochrome $b$ sequences. Mol Phylogen Evol. 14:1-10.

Lavoué S, Hopkins CD, Kadem Toham A. 2004. The Petrocephalus (Pisces, Osteoglossomorpha, Mormyridae) of Gabon, Central Africa, with the description of a new species. Zoosystema 26:511-535.

Lavoué S, Sullivan JP. 2004). Simultaneous analysis of five molecular markers provides a wellsupported phylogenetic hypothesis for the living bony-tongue fishes (Osteoglossomomorpha: Teleostei). Mol Phylogen Evol. 33:171-185.

Leviton AE, Gibbs RH, Heal E, Dawson CE. 1985. Standards in herpetology and ichthyology: part I. Standard symbolic codes for institutional resource collections in herpetology and ichthyologhy. Copeia 1985:802-832.

Lissmann HW, Machin KE. 1958. The mechanism of object location in Gymnarchus niloticus and similar fish. J Exp Biol. 35:451-486.

Machordom A, Doadrio I. 2001. Evidence of a cenozoic Betic-Kabilian connection based on freshwater fish phylogeography (Luciobarbus, Cyprinidae). Mol Phylogen Evol. 18:252-263.

Markowski B, Baier B, Kramer B. 2008. Differentiation in electrical pulse waveforms in a pair of sibling Dwarf Stonebashers, Pollimyrus castelnaui and P. marianne: possible mechanisms and functions (Mormyridae, Teleostei). Behaviour 145:115-135.

McGarigal K, Cushman S, Stafford S. 2000. Multivariate statistics for wildlife and ecology research. New York: Springer Verlag.

Meyer JH. 1982. Behavioral responses of weakly electric fish to complex impedances. J Comp Physiol A. 145:459-470. 
Moore AE, Larkin, PA. 2001. Drainage evolution in south-central Africa since the breakup of Gondwana. South Afr J Geol. 104:47-68.

Penrith MJ. 1982. Additions to the checklist of southern African freshwater fishes and a gazetteer of south-western Angolan collecting sites. J Limnol Soc south Afr. 8:71-75.

Posada D, Crandall KA. 1998. MODELTEST: testing the model of DNA substitution. Bioinformatics 14:817-818.

Saitou N, Nei M. 1987. A neighbor-joining method: a new method for reconstructing phylogenetic trees. Mol Biol Evol. 4:406-425.

Skelton PH. 1994. Diversity and distribution of freshwater fishes in East and Southern Africa. Musée roy Afr centr (Tervuren): Ann Sér octav/Sci Zool. 275:95-131.

Skelton P. 2001. A complete guide to the freshwater fishes of southern Africa. Cape Town: Struik Publishers.

Stankiewicz J, de Wit MJ. 2006. A proposed drainage evolution model for Central Africa - did the Congo flow east? J Afr Earth Sci. 44:75-84.

Stieler A. 1910. Hand-Atlas. Gotha: Julius Perthes.

Sullivan JP, Lavoué S, Arnegard ME, Hopkins CD. 2004. AFLPs resolve phylogeny and reveal mitochondrial introgression within a species flock of African electric fish (Mormyroidea: Teleostei). Evol Int J Org Evol. 58:825-841.

Sullivan JP, Lavoué S, Hopkins CD. 2000. Molecular systematics of the African electric fishes (Mormyroidea: Teleostei) and a model for the evolution of their electric organs. J Exp Biol. 203:665-683.

Sullivan JP, Lavoué S, Hopkins CD. 2002. Discovery and phylogenetic analysis of a riverine species flock of African electric fishes (Mormyridae: Teleostei). Evol Int J Org Evol. 56:597-616.

Swofford DL. 2002. PAUP* phylogenetic analysis using parsimony (*and other methods), version 4. Sunderland (MA): Sinauer Associates.

Tabachnick BG, Fidell LS. 2000. Using multivariate statistics. Boston (MA): Allyn and Bacon.

Taverne L. 1971a. Note sur la systématique des poissons Mormyriformes. Le problème des genres Gnathonemus Gill, Marcusenius Gill, Hippopotamyrus Pappenheim, Cyphomyrus Myers et les nouveaux genres Pollimyrus et Brienomyrus. Rev Zool Bot Afr. 84(1-2):99-110.

Taverne L. 1971b. Ostéologie des genres Marcusenius Gill, Hippopotamyrus Pappenheim, Cyphomyrus Myers, Pollimyrus Taverne et Brienomyrus Taverne (Pisces Mormyriformes). Ann Mus roy Afr centr Sci zool. 188:x-144+ 3 plates.

Taverne L. 1972. Ostéologie des genres Mormyrus Linné, Mormyrops Müller, Hyperopisus Gill, Isichthys Gill, Myomyrus Boulenger, Stomatorhinus Boulenger et Gymnarchus Cuvier. Considérations générales sur la systématique des poissons de l'ordre des Mormyriformes. Ann Mus roy Afr centr Sci zool. 200:1-194 + 2 plates.

Van der Waal BCW, Skelton PH. 1984. Check list of fishes of Caprivi. Madoqua (Windhoek). 13(4):303-320.

Von der Emde G. 1990. Discrimination of objects through electrolocation in the weakly electric fish, Gnathonemus petersii. J Comp Physiol A. 167:413-421.

Westby GWM. 1984. Simple computer model accounts for observed individual and sex differences in electric fish signals. Anim Behav (Lond). 32:1254-1256.

Wilson AC, Ochmann H, Parager EM. 1987. Molecular-timescale for evolution, Trends Genetics, 3:241-247. 


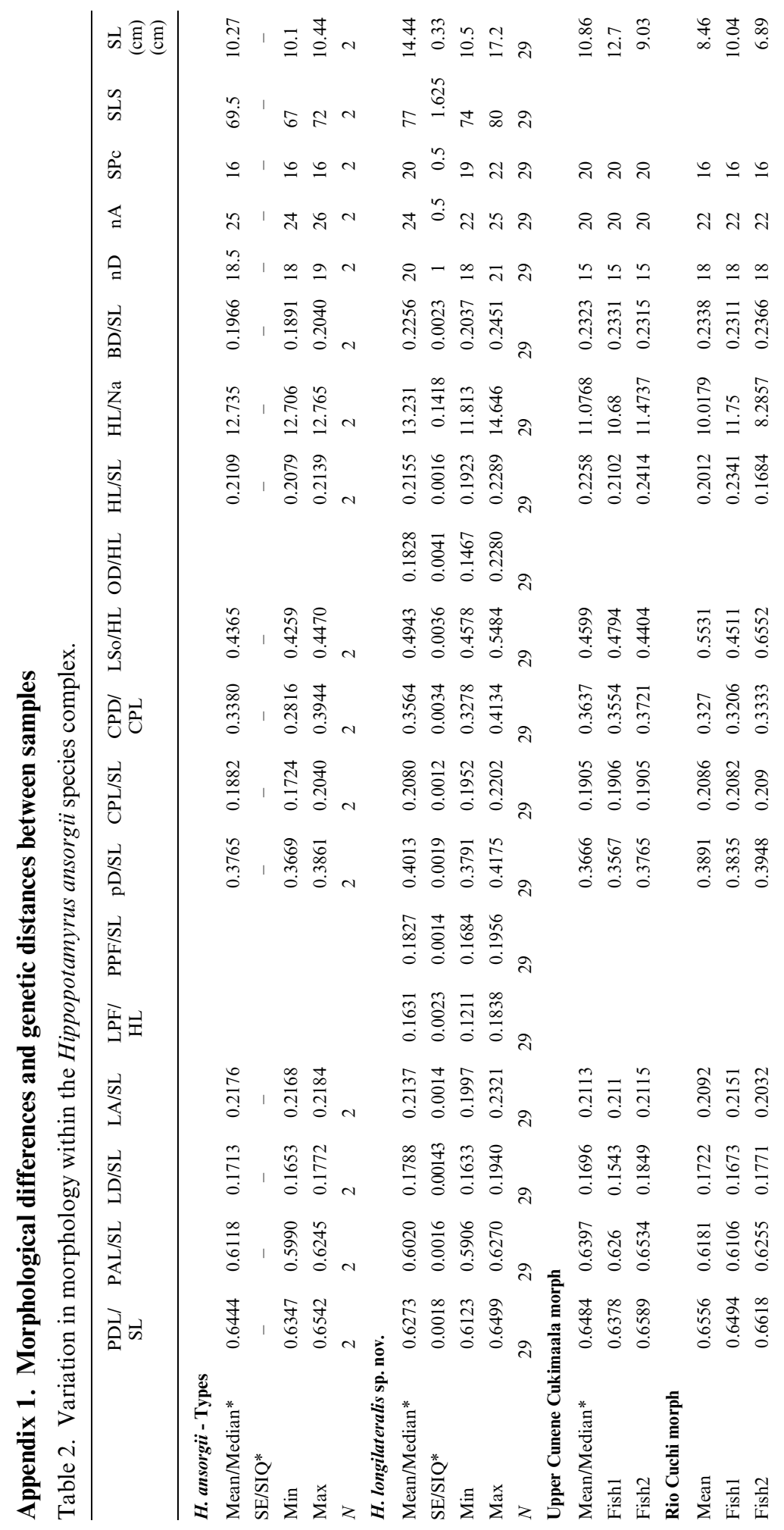




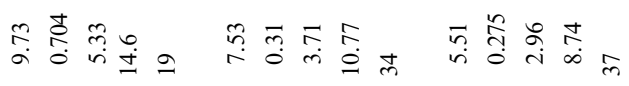

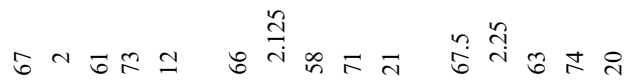
중ำ ส

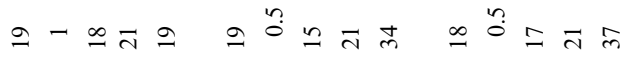

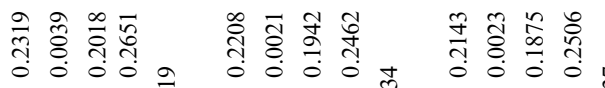

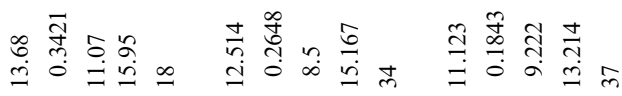

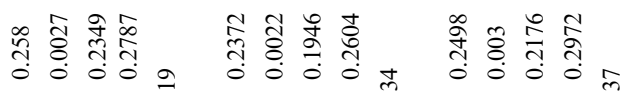
$\frac{0}{2}$

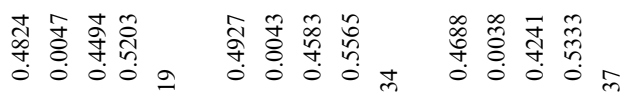

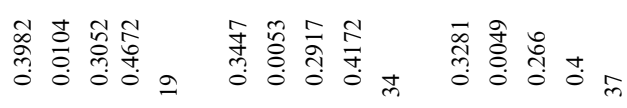

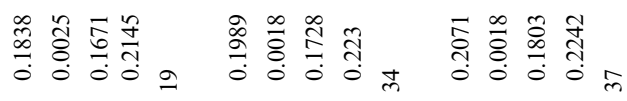

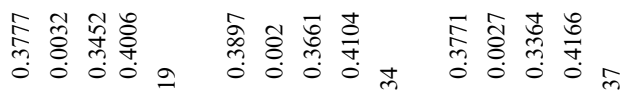

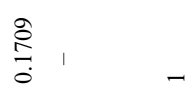

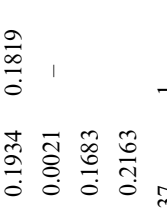

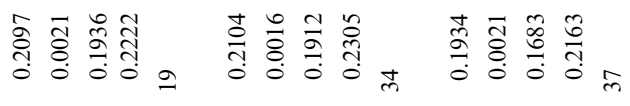

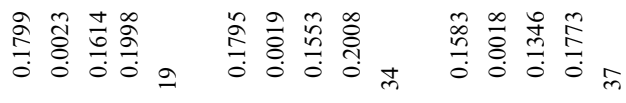

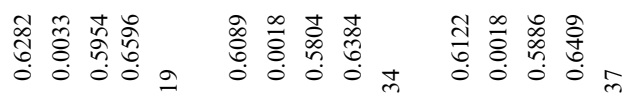

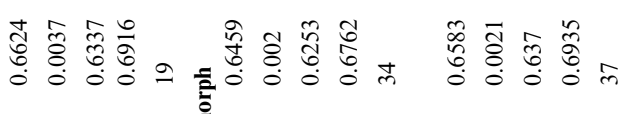

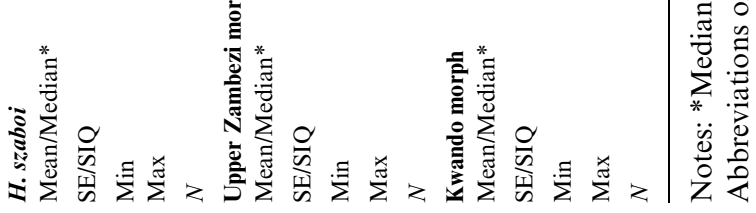


Table 3. Principal components analysis on correlations for morphological characters from four members of the Hippopotamyrus ansorgii species complex, that is, the Upper Zambezi morph, the Kwando morph, Hippopotamyrus szaboi and Hippopotamyrus longilateralis sp. $\mathrm{n}$. $(N=119)$.

\begin{tabular}{|c|c|c|c|c|c|c|c|}
\hline Eigen value & 5.6575 & 2.8758 & 1.4264 & 0.9754 & 0.7531 & 0.5525 & 0.4077 \\
\hline Per cent & 40.411 & 20.541 & 10.188 & 6.967 & 5.379 & 3.946 & 2.912 \\
\hline Cum Per cent & 40.411 & 60.952 & 71.14 & 78.108 & 83.487 & 87.433 & 90.345 \\
\hline \multicolumn{8}{|l|}{ Eigenvectors } \\
\hline PDL/SL & -0.3174 & 0.289 & 0.0472 & 0.088 & 0.1088 & 0.1127 & -0.1825 \\
\hline PAL/SL & -0.1476 & 0.4562 & 0.0602 & 0.2066 & 0.0805 & 0.2794 & 0.2774 \\
\hline $\mathrm{LD} / \mathrm{SL}$ & 0.3109 & 0.2048 & -0.3279 & -0.2694 & 0.1782 & 0.1383 & 0.055 \\
\hline LA/SL & 0.3275 & 0.1409 & -0.3045 & -0.255 & -0.0927 & -0.0806 & 0.082 \\
\hline $\mathrm{pD} / \mathrm{SL}$ & 0.3107 & -0.2152 & -0.1886 & -0.1742 & 0.3014 & -0.0132 & 0.3485 \\
\hline CPL/SL & -0.0173 & -0.5119 & -0.0067 & 0.2304 & 0.2945 & 0.258 & -0.0187 \\
\hline CPD/CPL & 0.1941 & 0.4255 & 0.0583 & 0.2383 & -0.0135 & -0.4837 & 0.2249 \\
\hline LSo/HL & 0.2153 & 0.0301 & -0.3018 & 0.5004 & -0.5425 & 0.4312 & 0.03 \\
\hline HL/SL & -0.3251 & 0.2148 & 0.0624 & -0.114 & 0.3474 & 0.2454 & 0.1359 \\
\hline $\mathrm{BD} / \mathrm{SL}$ & 0.2455 & 0.2589 & -0.2603 & 0.1598 & 0.4203 & 0.1056 & -0.6563 \\
\hline $\mathrm{nD}$ & 0.2809 & 0.0841 & 0.3683 & -0.3262 & -0.0721 & 0.5533 & 0.0671 \\
\hline $\mathrm{nA}$ & 0.2491 & 0.1018 & 0.5051 & -0.2324 & -0.2344 & -0.0317 & -0.3521 \\
\hline $\mathrm{SPc}$ & 0.3022 & 0.067 & 0.3426 & 0.3126 & 0.2812 & 0.0504 & 0.3285 \\
\hline SLS & 0.3074 & -0.1455 & 0.2898 & 0.3532 & 0.181 & -0.1264 & -0.1456 \\
\hline \multicolumn{8}{|c|}{ Component loadings } \\
\hline PDL/SL & -0.755 & 0.4902 & 0.0564 & 0.0869 & 0.0945 & 0.0838 & -0.1165 \\
\hline PAL/SL & -0.3511 & 0.7736 & 0.0719 & 0.2041 & 0.0699 & 0.2076 & 0.1771 \\
\hline $\mathrm{LD} / \mathrm{SL}$ & 0.7394 & 0.3474 & -0.3917 & -0.266 & 0.1546 & 0.1028 & 0.0351 \\
\hline LA/SL & 0.779 & 0.2389 & -0.3637 & -0.2519 & -0.0804 & -0.0599 & 0.0523 \\
\hline $\mathrm{pD} / \mathrm{SL}$ & 0.739 & -0.365 & -0.2253 & -0.172 & 0.2616 & -0.0098 & 0.2225 \\
\hline CPL/SL & -0.0412 & -0.8681 & -0.008 & 0.2275 & 0.2556 & 0.1918 & -0.0119 \\
\hline CPD/CPL & 0.4616 & 0.7216 & 0.0696 & 0.2354 & -0.0117 & -0.3595 & 0.1436 \\
\hline LSo/HL & 0.5121 & 0.051 & -0.3604 & 0.4942 & -0.4707 & 0.3205 & 0.0191 \\
\hline HL/SL & -0.7733 & 0.3643 & 0.0746 & -0.1125 & 0.3015 & 0.1824 & 0.0867 \\
\hline $\mathrm{BD} / \mathrm{SL}$ & 0.5839 & 0.439 & -0.3109 & 0.1578 & 0.3648 & 0.0785 & -0.419 \\
\hline $\mathrm{nD}$ & 0.668 & 0.1425 & 0.4398 & -0.3222 & -0.0625 & 0.4113 & 0.0428 \\
\hline $\mathrm{nA}$ & 0.5925 & 0.1727 & 0.6033 & -0.2295 & -0.2034 & -0.0236 & -0.2248 \\
\hline $\mathrm{SPc}$ & 0.7188 & 0.1137 & 0.4091 & 0.3088 & 0.244 & 0.0375 & 0.2098 \\
\hline SLS & 0.7312 & -0.2467 & 0.3461 & 0.3488 & 0.1571 & -0.094 & -0.0929 \\
\hline
\end{tabular}




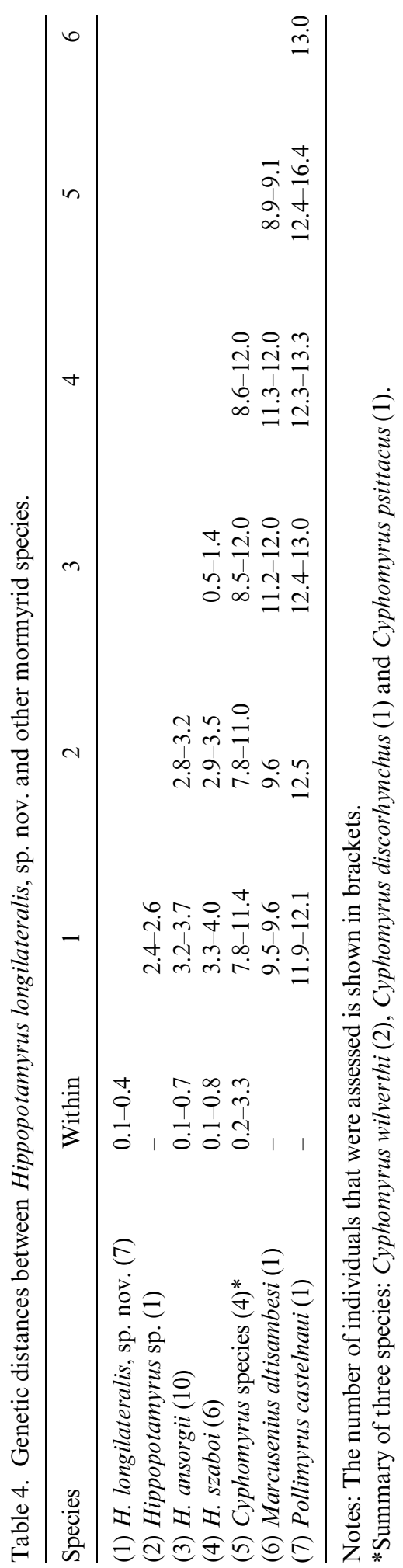




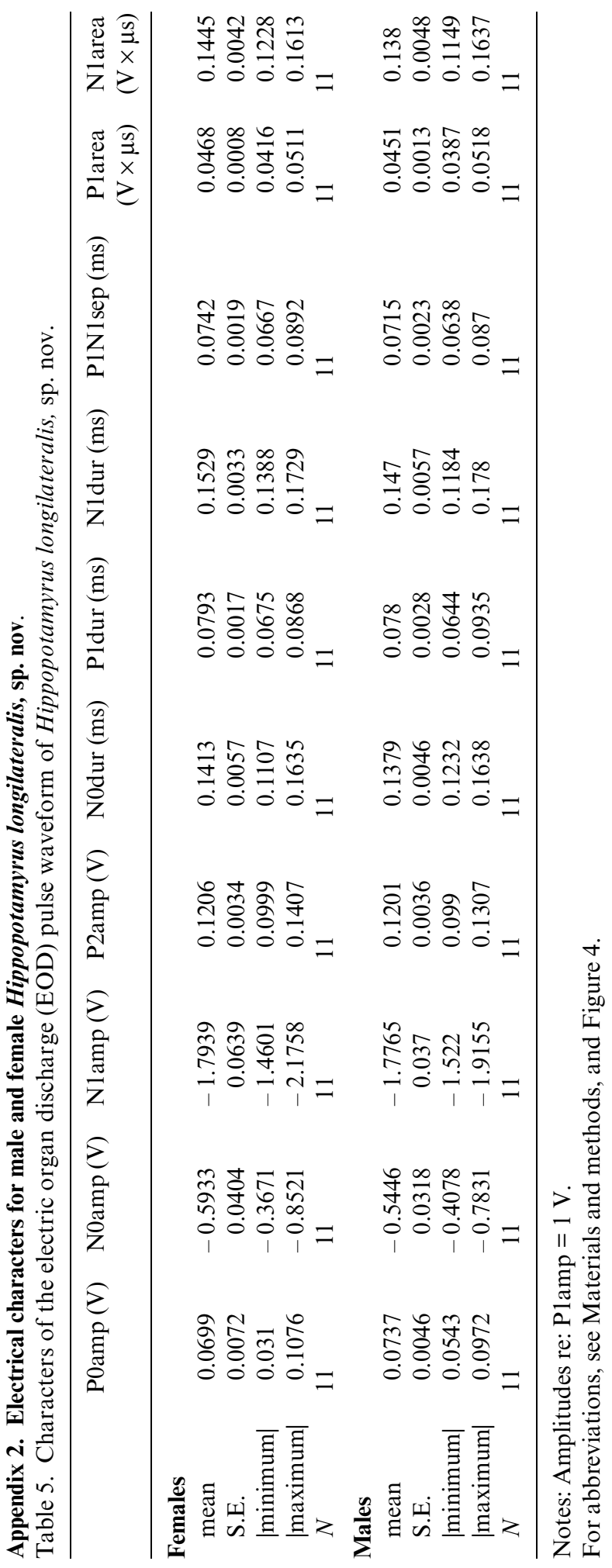

